\title{
The Anatomy of the Antarctic Polar Front in the Drake Passage
}

\author{
TERRENCE M. JoyCE \\ Woods Hole Oceanographic Institution, Woods Hole. Massachusetts 02543
}

WALTER ZENK

Institut für Meereskunde, Kiel, West Germany

JOHN M. TOOLE

Woods Hole Oceanographic Institution, Woods Hole, Massachusetts 02543

\begin{abstract}
An intensive three-dimensional survey of the Antarctic Polar Front was made in the Drake Passage in March 1976. The front, which was imbedded within one of the high-velocity cores of the circumpular current, is viewed as a water mass boundary demarking the northern extent of near-surface antarctic waters. Within the front, water masses are observed to intrude, one above the other, with characteristic vertical scales of $50-100 \mathrm{~m}$. The intrusions are horizontally anisotropic, being elongated in the alongstream direction and constrained primarily to the upper $800 \mathrm{~m}$ of the front. The spatial and temporal persistence of the variability is examined through the analysis of continuous vertical profiles of horizontal velocity, temperature, salinity, and oxygen with discrete sampling of nutrients. Analysis of the velocity data showed the mean current flowing to the NNE with speeds of the order of $30-40 \mathrm{~cm} \mathrm{~s}^{-1}$ in the upper $600 \mathrm{~m}$. with temporal variability over a 28 -hour 'yo-yo' due primarily to internal gravity waves. The thermohaline variability was not internarwave induced but rather was associated with nearly isentropic advection of different water masses across the front. Cold fresh and warm salty intrusions did not conserve potential density, however, and double-diffusive transfers are strongly suggested as being crucial to an understanding of the dynamics of the intrusions. Applying a model (Joyce, 1977) for lateral mixing we estimate poleward temperature and salinity fluxes due to interleaving of $0.086^{\circ} \mathrm{C} \mathrm{cm} \mathrm{s}^{-1}$ and $0.069^{\circ}{ }^{\circ}$ $\mathrm{cm} \mathrm{s} \mathrm{s}^{-1}$, respectively. If these values are typical, interleaving could play a significant role in large-scalc balance of salt and, to a lesser extent, heat for the Southern Ocean.
\end{abstract}

\section{INTRODUCTION}

At a recent symposium on oceanic fronts the definition of what constituted a front, though gingerly avoided, inevitably emerged to hold the attention of the conferees. This question is of relevance to the Antarctic Polar Front, as several differing definitions are in the literature [c.f., Gordon, 1971], and the expectation is that more may come. The operational definition used in this paper follows that of Botnikov [1963], who used the northern extent of the $2^{\circ} \mathrm{C}$ isotherm at depths of between 100 and $300 \mathrm{~m}$. In winter this isotherm intersects the free surface near the 'front,' while in summer the near-surface waters are warmed, leaving a subsurface minimum temperature $\left(T_{\mathrm{min}}\right)$ layer with temperatures of $\leq 2^{\circ} \mathrm{C}$.

In March/April 1976 the R. V. Thompson (University of Washington) and the AGS Yelcho (Chilean Navy) were operating in the Drake Passage as part of a program of International Southern Occan Studies (Isos). All field work, of which ours was a part, is summarized elsewhere [Nowlin et al., 1976; Joyce, 1976a; Patterson and Sievers, 1976]. We will present results from a three-dimensional survey designed to map synoptically the interleaving water masses within the polar front and an analysis of repeated profiles within the front taken to study the spatial and temporal persistence of the variability. The primary instruments used were a Woods Hole Oceanographic Institution (W.H.O.I.)/Brown conductivity, temperature, depth (CTD) profiler with a Beckman dissolved oxygen monitor and a profiling current meter (PCM) of the Aanderaa type which guided, as it slowly sank, on the CTD conducting cable. We will be directed in our analysis of the

Copyright (C) 1978 by the American Geophysical Union. data by a desire to relate the observations to the dynamics of different scales of motion ranging from $T / S$ microstructure to lateral mixing and the Antarctic Circumpolar Current (AACC). First a brief review will be made of the large-scale context in which our measurements were made.

The Drake Passage is the narrowest constriction $(800 \mathrm{~km})$, in the sense of continental land barriers, to the AACC. Within this narrow confine a broad variety of water masses can be found. Some recent Isos measurements from the passage and western Scotia Sea have been presented [Nowlin et al., 1977, Gordon et al., 1977] and illustrate that water masses occur in zones aligned parallel to the AACC. Furthermore, the boundaries between these zones (according to the first reference above) are associated with rapid increases in the slopes of constant potential density surfaces and hence geostrophic shear. With reference to the Figures $I$ and 2 we will discuss a cross-passage hydrographic section of temperature, salinity, potential density, and oxygen which was collected from the Thompson between February 26 and March 3, 1976. Except for Figure $2 c$ these sections have not been published and have been generously given to us by Worth Nowlin. The station spacing (Figure 1) for the section is nominally $45 \mathrm{~km}$.

The polar front (following Botnikov [1963]) lies betweeil stations 38 and 40 from Figure $2 a$. Southward, the upper waters are colder and more oxygenated than waters to the north. In this section and others reported by Nowlin et al. [1977] the frontlike feature in potential density in the center passage (Figure $2 c$ ) is coincident with the polar front, thus giving further impetus for using the Botnikov definition. Other density steps near stations 30 and 48 can be associated with the subantarctic front and the Wedell-Scotia confluence [Gordon, 


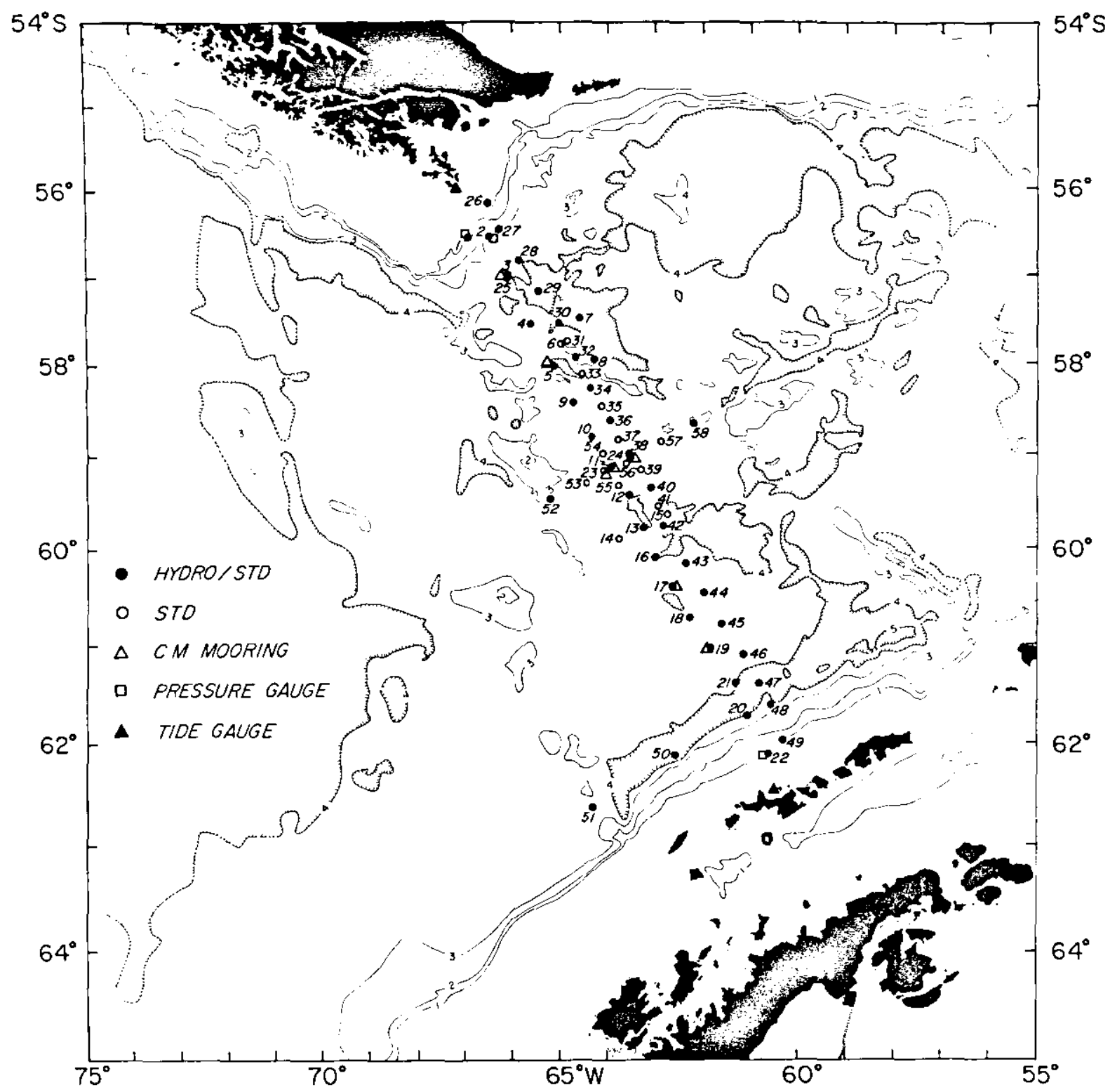

Fig. 1. Sumnary of legs I and II stations from the R. V. Thompson during FDRAKE 76. Water depth is in kilometers. A hydrographic section from stations $26-49$ will be shown in Figure 2.

1967], respectively, and show the banded nature of the AACC. Given three fronts, there are four zones; the polar front zone. between stations 32 and 38 , is characterized by interleaving water masses and large lateral changes in the $T / S$ structure. Our small-scale survey was set, phenomenologically, within the southern end of this zone where it abuts the $T_{\text {min }}$ water to the south. We hope to establish that the process of interleaving is a natural result of large lateral $T / S$ changes and that the polar front zone is a region of mixing between antarctic and subantarctic waters. The absence of interleaving within other zones merely attests to their relative uniformity in lateral water mass structure.

On the leg following the hydrographic section above, our small-scale survey was carried out. Between March 10 and March 24 a large meinder in the polar front was observed to grow and eventually pinch off between March 28 and March 30 into a cyclonic ring of antarctic waters [Joyce and Patterson, 1977]. This cyclogencsis closely follows our survey described in the next section and leads us to wonder about the structure or existence of a tranquil polar front, if such a thing exists. Following the spatial survey we will present results from a two-inertial period $\left(\tau_{1} \sim 14\right.$ hours $)$ time series of CTD and PCM profiles. Our discussion then attempts to explore the dynamical significance of our results.

\section{SPatial Survey}

Between March 21 and March 23, CTD stations 25-43 were taken over a 52-hour period at locations shown in Figure 3. The meandering of the polar front as inferred from XBT's and reported by Joyce and Patterson is indicated by coded lines in the figure. Stations 25-39 comprise a section normal to the local front orientation, while stations $40-43$ are nearly parallel to the front. Since the ship tracks in the region were quite dense and previous topographic charts led us to believe that the bottom was flat, we have included a chart (Figure 4) of the local bathymetry, the most significant feature of which is a newly discovered seamount rising about $1000 \mathrm{~m}$ above the surrounding ocean floor. The distance between stations 25 and 


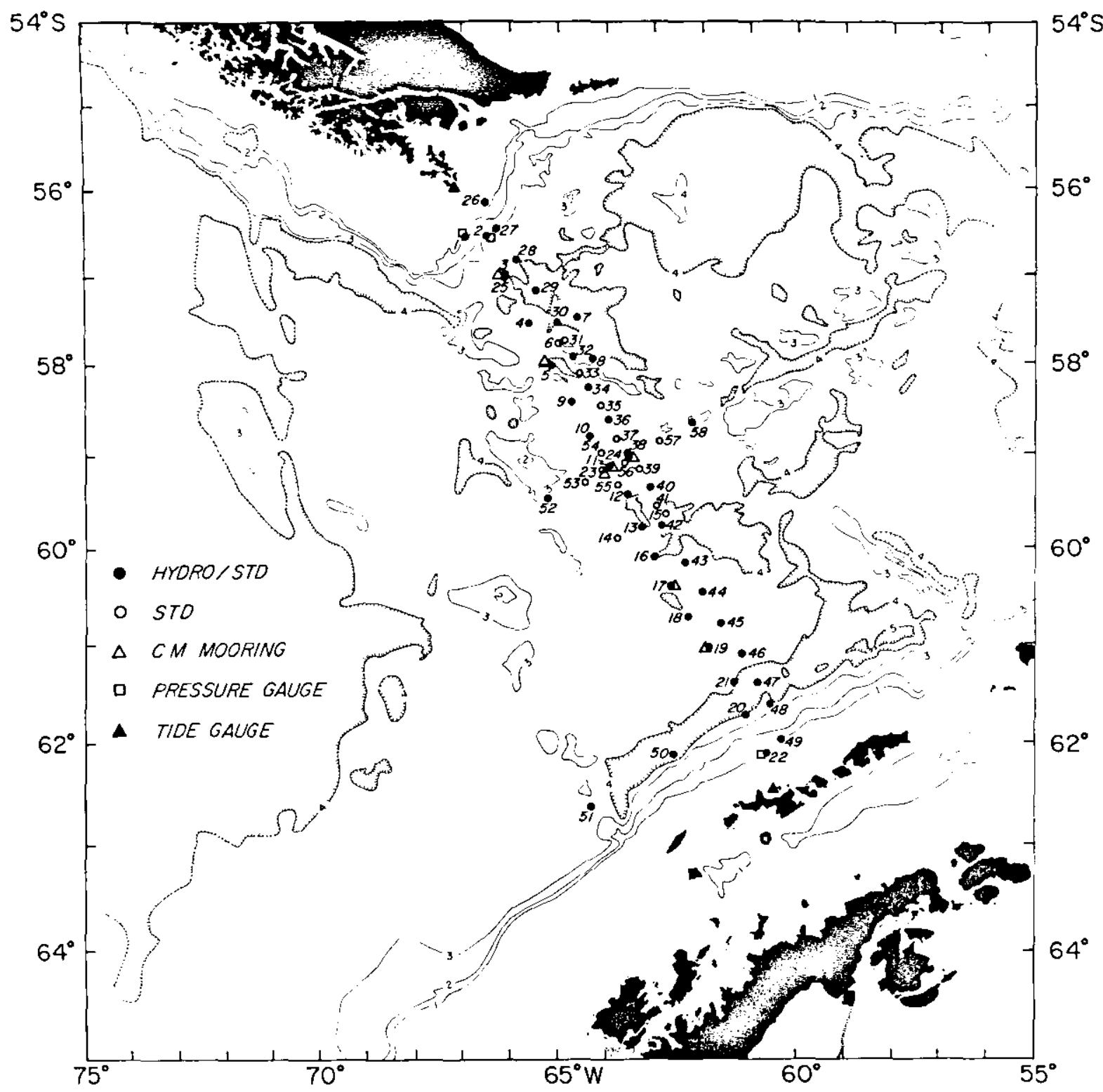

Fig. 1. Sumnary of legs I and II stations from the R. V. Thompson during FDRAKE 76. Water depth is in kilometers. A hydrographic section from stations $26-49$ will be shown in Figure 2.

1967], respectively, and show the banded nature of the AACC. Given three fronts, there are four zones; the polar front zone, between stations 32 and 38, is characterized by interleaving water masses and large lateral changes in the $T / S$ structure. Our small-scale survey was set, phenomenologically, within the southern end of this zone where it abuts the $T_{\text {min }}$ water to the south. We hope to establish that the process of interleaving is a natural result of large lateral $T / S$ changes and that the polar front zone is a region of mixing between antarctic and subantarctic waters. The absence of interleaving within other zones merely attests to their relative uniformity in lateral water mass structure.

On the leg following the hydrographic section above, our small-scale survey was carried out. Between March 10 and March 24 a large meander in the polar front was observed to grow and eventually pinch of between March 28 and March 30 into a cyclonic ring of antarctic waters [Joyce and Patterson, 1977]. This cyclogenesis closely follows our survey described in the next section and leads us to wonder about the structure or existence of a tranquil polar front, if such a thing exists. Following the spatial survey we will present results from a two-inertial period $\left(\tau_{i} \sim 14\right.$ hours) time series of CTD and PCM profiles. Our discussion then attempts to explore the dynamical significance of our results.

\section{SPatial SURvey}

Between March 21 and March 23, CTD stations 25-43 were taken over a 52-hour period at locations shown in Figure 3. The meandering of the polar front as inferred from XBT's and reported by Joyce and Patterson is indicated by coded lines in the figure. Stations 25-39 comprise a section normal to the local front orientation, while stations $40-43$ are nearly parallel to the front. Since the ship tracks in the region were quite dense and previous topographic charts led us to believe that the bottom was flat, we have included a chart (Figure 4) of the local bathymetry, the most significant feature of which is a newly discovered seamount rising about $1000 \mathrm{~m}$ above the surrounding ocean floor. The distance between stations 25 and 

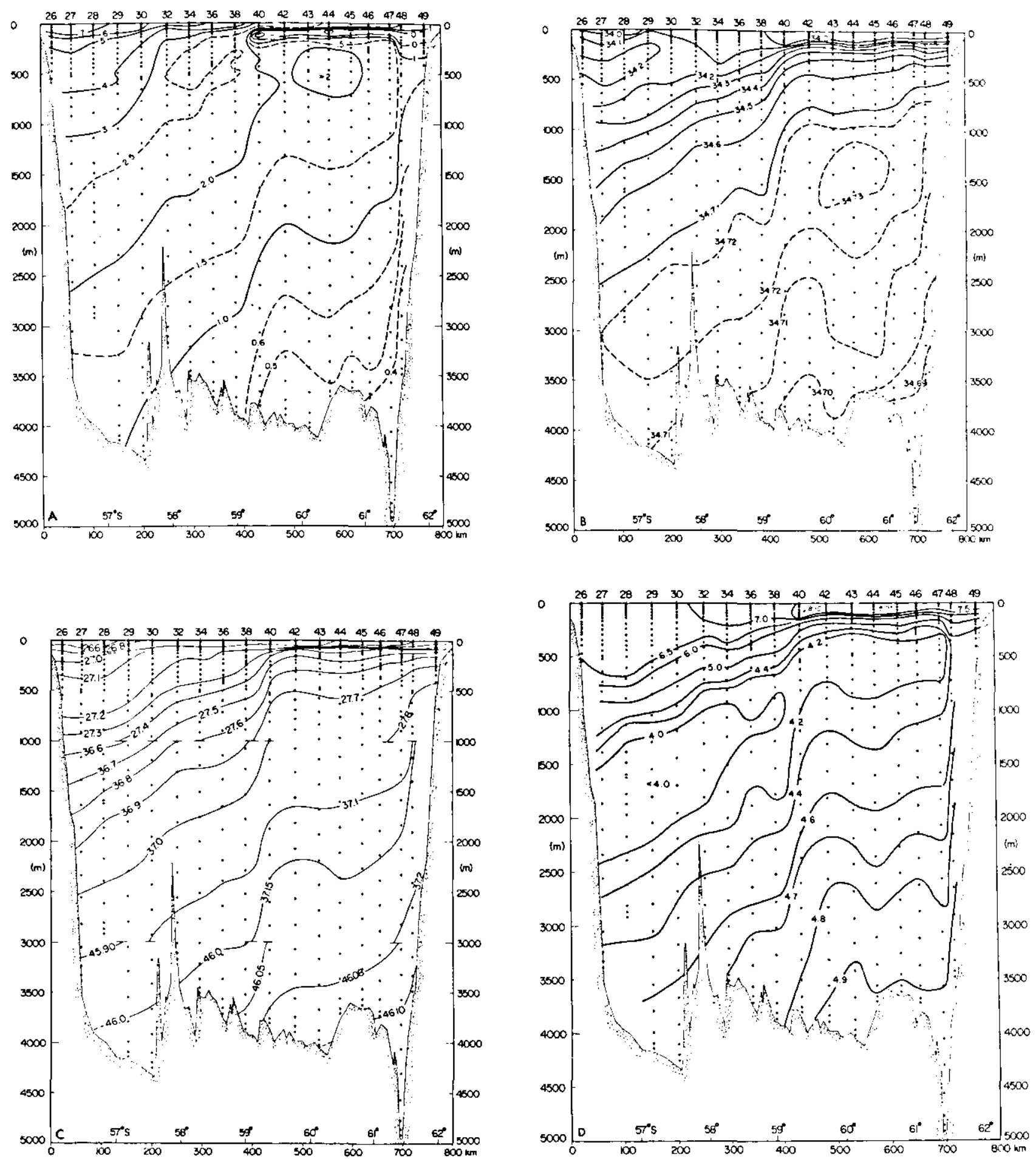

Fig. 2. Contoured data from the cross-passage section during FDRAKE 76. (a) Temperature, $(b)$ salinity, and $(c)$ potential density relative to 0,2000 , and $4000 \mathrm{dbar}$, and $(d)$ dissolved oxygen, in milliliters per liter.

39 , approximately $70 \mathrm{~km}$, though small, spans large differences in water masses. Selected stations from the survey have been plotted on a $\theta / S$ diagram (Figure 5 ). Because the oxygen probe could not be used safely below $3000 \mathrm{dbar}$, this was the maximum working depth for all stations (later sections have had only the upper $1500 \mathrm{dbar}$ contoured). (The oxygen probe, with a 15-s time constant, needed to be lag corrected in a manner similar to but more extensive than the temperature probe [see Fofonoff et al., 1974]. This process tends to enhance noise in the $\mathrm{O}_{2}$, the level of which is obvious from the deep water in
Figure 6.) By our definition, stations 25 and 26 in Figure 5 are poleward of the front, while the others are equatorward. Though stations 25 and 26 are separated by only $6 \mathrm{~km}$, a surprising number of the fluctuations do not extend even this distance. The contorted feature on station 25 near $\theta=1.5^{\circ} \mathrm{C}, S$ $=34.07 \%$ consisting of numerous loops in the $\theta / S$ diagram does not appear at all on station 26. The intrusion of cold fresh water near $\theta=1.5^{\circ} \mathrm{C}, S=34.20 \%$ is traceable betw'een these two stations but does not extend across the entire section. These features are consistent with the earlier large-scale sec- 


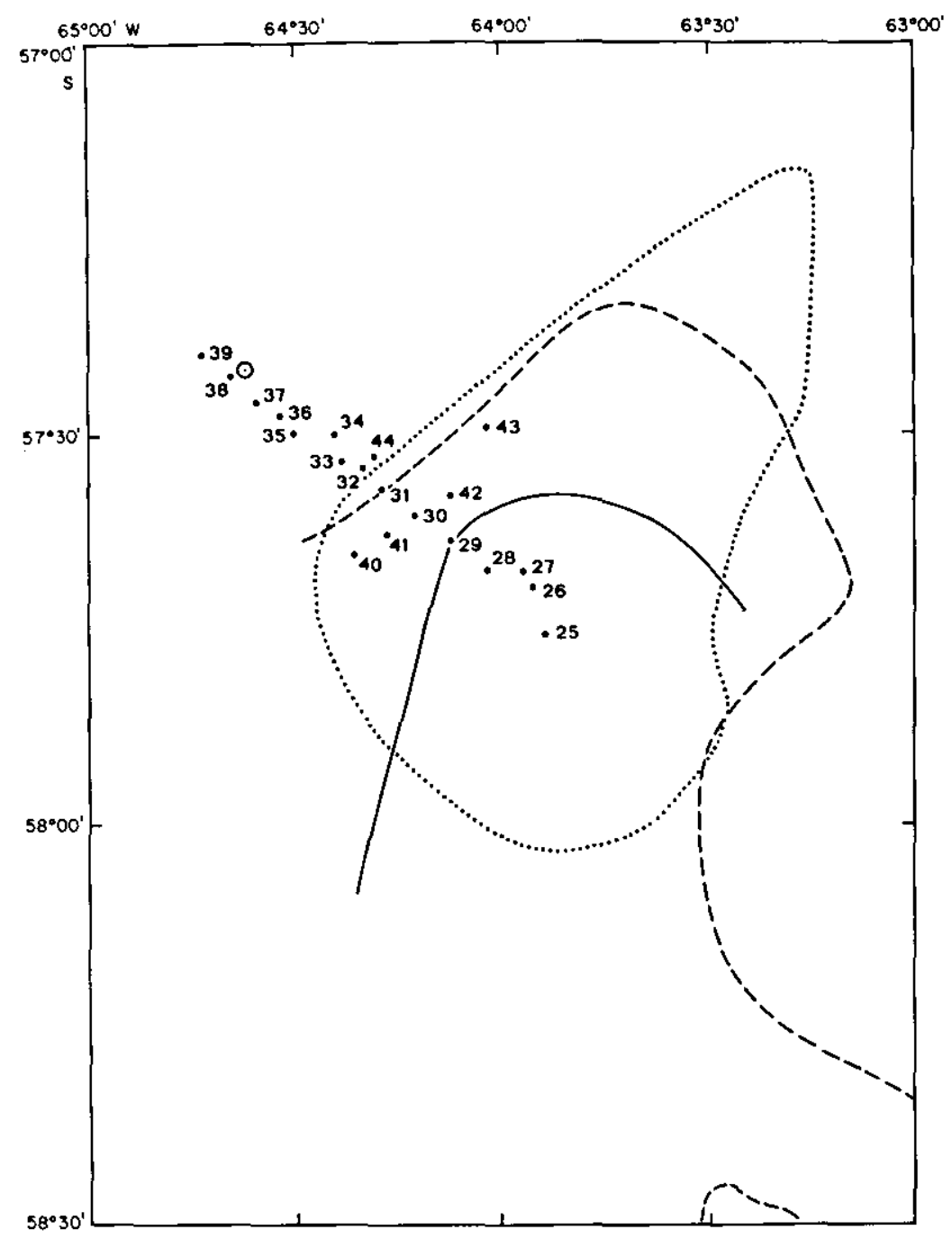

Fig. 3. CTD stations from leg 1II, denoted by dots, and time series site location, denoted by circled dot, for CTD stations 7-24. Also shown is polar front location from Joyce and Patterson [1977] for the time periods March 16, 0000, to March 20, 2359 (solid curve), March 21, 0000, to March 26, 2359 (dashed curve), and March 27, 0000, to March 30, 2359 (dotted curve).

tion near the polar front. The gross trend is for stations south of the front to be colder, fresher, and more oxygenated than those north of the front at the same density. The vertical variability, called interleaving or intrusions, is evident in Figure 6. Intrusions of warm, salty, low $\mathrm{O}_{2}$ waters are interspersed with cold, fresh, high $\mathrm{O}_{2}$ waters of a more southerly origin. Below $800 \mathrm{dbar}$, most of the interleaving disappears. The large multiple inversions of $T, S$, and $\mathrm{O}_{2}$ are absent from $\sigma_{t}$, which except for small regions is largely monotonic, increasing with depth. This fact has given rise to the phrase density compensating' for these intrusions [Gordon et al., 1977], a term we will carefully examine later. Although the interleaving $T, S$, and $\mathrm{O}_{2}$ layers appear correlated, in the following sections the contoured fields appear visually different. This is because the variability is imbedded within a slowly changing component which behaves differently for each variable. The temperature (refer to Figure 6 for the following), after decreasing below $2^{\circ} \mathrm{C}$, increases to a maximum near $750 \mathrm{dbar}$ and then decreases monotonically with depth. The salinity gradually increases to a maximum value of $34.72 \%$ at 2400 dbar and then decreases, while the dissolved oxygen decreases to a minimum value near $4.00 \mathrm{ml} / \mathrm{l}$ at $1200 \mathrm{dbar}$ and thereafter increases. All of these larger-scale trends are in general agreement with the discrete sample data at the polar front in Figure 2 and in the appendix, which contains the discrete nutrient and oxygen data from our close-spaced survey. Our continuous, small-scale survey has permitted us to include a different, smaller scale of variability in the front, that of the interleaving waters.

In Figure 7 a section perpendicular to the front (stations 2539 ) appears in the right column, while that parallel to the front appears on the left. Note that the common station for each is station 31 , which was chosen over station 30 (refer to Figure 3 ) because it made the parallel section more 'mappable' on the average. Obviously, with surface currents of $30 \mathrm{~cm} / \mathrm{s}$ (these will be presented later) and a rapidly evolving front, even a 2day survey cannot hope to be truly synoptic, especially for these scales. The temperature section shows the cold single $T_{\mathrm{m} ! n}$ layer of stations $25-27$ splitting into at least two large layers separated by a warm wedge at $500 \mathrm{dbar}$. These large layers cannot be followed for any distance greater than about $10 \mathrm{~km}$ (across the front). Along the front, however, layers are more extensive. The cold layer of water $<2.5^{\circ} \mathrm{C}$ centered at $700 \mathrm{dbar}$ is traceable from stations 43 to 40 and is being fractured by a warmer intrusion. The thin cold layer at 400 
dbar extending from stations 41 to 42 does not in fact appear distinct in station 31 , which contains only one thicker cold layer. We have shown this thin layer to be continuous across station 31 and have invoked artistic license here, the rationale being that stations 31 and 41 were separated in time by 29 hours and are therefore not synoptic. In every other case we have included station 31 in the along-front section. We will postpone until later further discussion of the spatial and temporal persistence of the intrusions.

Above $500 \mathrm{dbar}$ in the cross-front section the salinity decreases southward, while deeper the reverse is true. Along a density surface, however, the salinity, with minor exceptions, decreases southward at all depths shown. At the northern side of the section, stations 37-39 have a weak salinity minimum $\left(S_{\mathrm{m} n}\right)$ layer which has been dashed in as the $34.15 \%$ isoline. This feature persisted throughout the time series and may be a shallow manifestation of antarctic intermediate water
(AAIW). This feature has been identified by Gordon et al. as a 'nearly isohaline layer.'

Between stations 27 and 37 the $\sigma_{t}$ surfaces $\geq 27.2$ slope uniformly poleward with a slope magnitude of about $0.7 \times$ $10^{-2}$ radians. This is very close to the slope at the polar front from Figure 2 and indicates to us that the large-scale section of Figure 2 was normal to the front and that based on either the subsurface temperature or the density fields the 'front' appears to be at least $20 \mathrm{~km}$ wide.

The dissolved oxygen field is highly convoluted where the $T_{m i n}$ layer erodes with the previously mentioned warm intrusion at $500 \mathrm{dbar}$, being visible in the cross-front $\mathrm{O}_{2}$ section as the intruding 6.0 - to $6.5-\mathrm{ml} / \mathrm{I}$ layer extending poleward from station 30. As in Figure $2 d$, the deep $\left(\mathrm{O}_{2}\right)_{\text {min }}$ layer slopes upward toward the pole with a thick low-oxygen intrusion of circumpolar deep water of probable Pacific origin visible near 1400 dbar at stations $38-39$. The process of interleaving in the

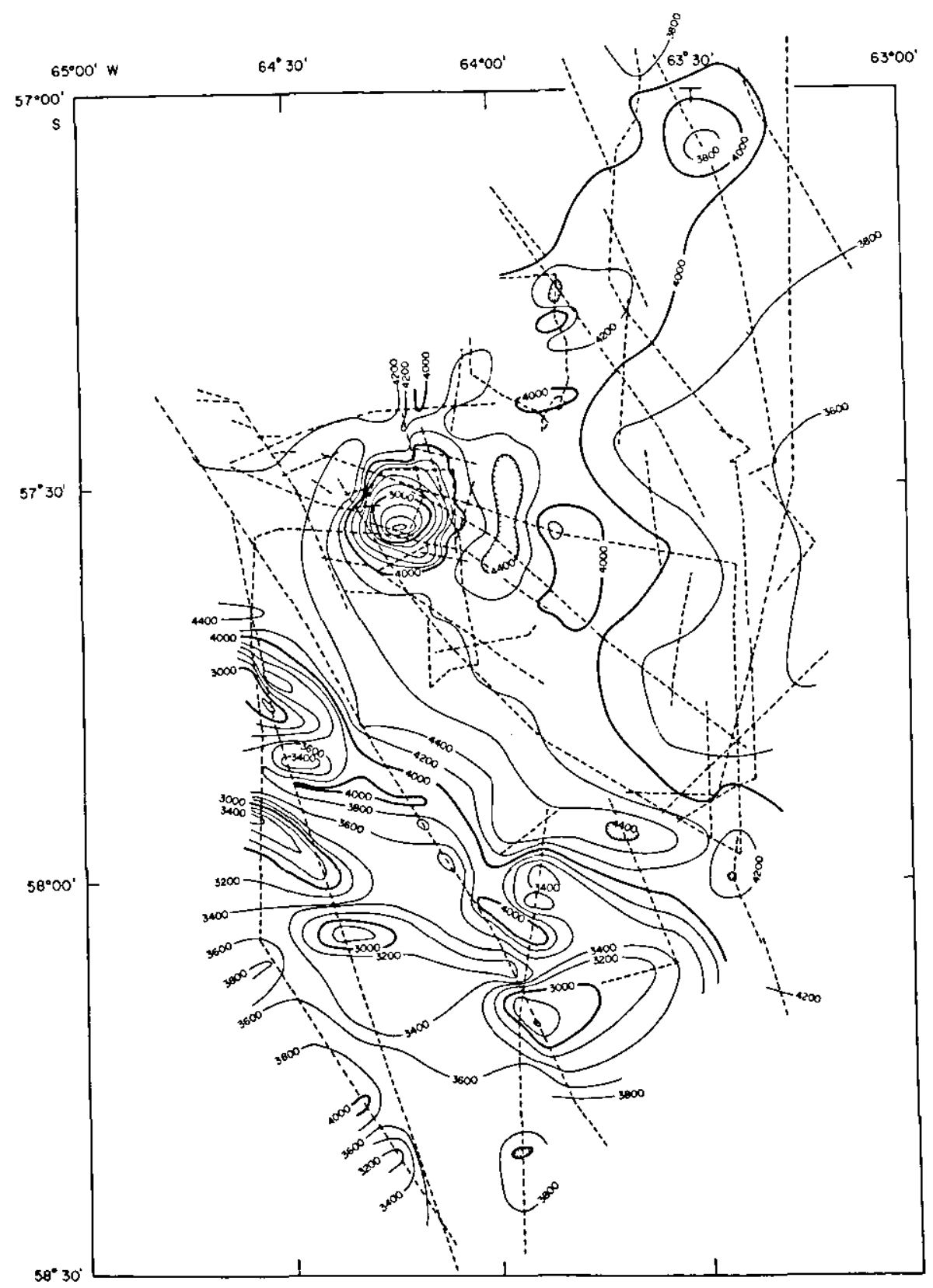

Fig. 4. Bottom topography (in meters) in the region of study. Dashed lines are ship tracks. 


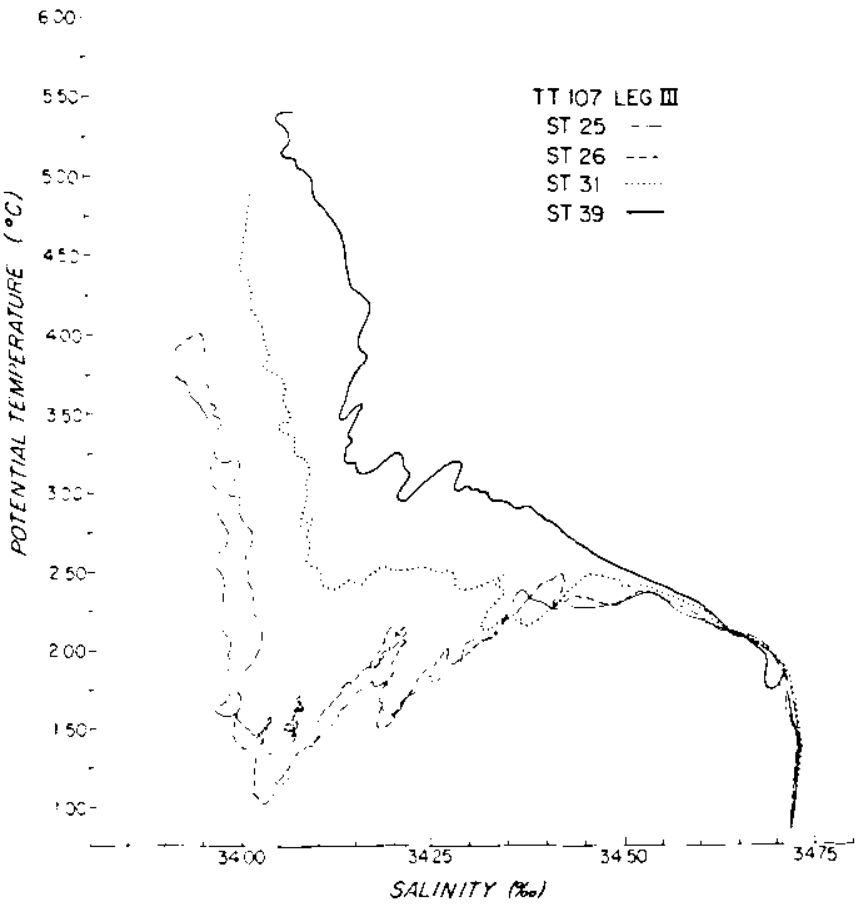

Fig. 5. A potential temperature-salinity diagram for stations 25, 26, 31 , and 39 .

deep water is most clearly revealed by $\mathrm{O}_{2}$ because substantial changes in dissolved oxygen content occur along a constint density surface at these depths.

The utility of the technique of isentropic analysis, first applied to the ocean by Montgomery [1938], will be employed later to study, among other things, the slope of intrusions relative to potential density surfaces. Though additional results are suggested in Figure 7 , we will turn to a time series of 17 CTD and 12 PCM profiles for further study of interleaving. Before departing from the spatial survey, the reader may wish to take note of the sections drawn from discrete nutrient and oxygen samples, which were collected with a rosette system and are described in the appendix.

\section{Time Sfriles}

For a 29-hour period between March 18 and March 20 a single geographical location $\left(57^{\circ} 25^{\prime} \mathrm{S}, 64^{\circ} 37^{\prime} \mathrm{W}\right)$ was maintained while 12 PCM and 17 CTD station profiles were made. Our positioning was relative to a radar transponder on a moored surface reference buoy. In fact, two such buoys were used for navigation in the spatial survey of the previous section; details can be found in the work of Joyce et al. [1976]. Because the AACC current was steady to the NNE (as we will soon see), the time series reference buoy, as inferred from satcllite lixes, had a watch circle of only $0.5 \mathrm{~km}$. Consequently, we believe our station keeping has an absolute accuracy of less than $1 \mathrm{~km}$.

Because of instrument constraints the PCM profiled to 600 dbar, while the CTD profiled to 1000 dbar for this phase. We will discuss the results from the two instruments separately for now, leaving a synthesis for later. For both instruments we begin by presenting the time mean followed by an analysis of the fluctuations. The latter will be statistical in nature, and we will assume stationarity, though in the second half of the period the variability may have been greater, and the vertical symmetry properties of the internal wave field may have changed. We note that a spectral gap between mesoscale and internal wave fluctuations is obsersed in mid-latitude moored current meter data [Fofonoff and Webster, 1971] at periods of $2-5 \tau_{i}$, the local inertial period $\tau_{i}$ for our area being 14 hours. Thus there is some rationale for thinking that the means represent a snapshot of the low-frequency scales of motion; this question can be better addressed by the Isos moored current meter data from the polar front.

For further reference the variability will be studied in vertical wave number space, the time mean being subtracted at each pressure.

$$
\psi_{1}=\operatorname{Re}\left(\int d k \psi, e^{i n z}\right)
$$

The cross spectrum $\mathrm{I}_{i j}$ between variables, $i, j$, can be written

$$
\Gamma_{i j}=\left\langle\hat{\psi}_{i}^{*}(\kappa) \hat{\psi}_{j}\left(\kappa^{\prime}\right) \delta \delta\left(\kappa-\kappa^{\prime}\right)\right.
$$

where the angle brackets represent a piece or ensemble average and $\delta\left(\kappa-\kappa^{\prime}\right)$ is a Kronecker delta function. Following Jenkins and Watts [1969] the cospectrum $C_{i j}$. quadspectrum $Q_{i j}$, coherence $R_{i j}$, and phase $\phi_{i j}$ are related to the cross spectrum by

$$
\Gamma_{t j}=C_{t j}-i Q_{u j}=\left[P_{t i} P_{j j}\right]^{12} R_{i j} \exp i \phi_{i j}
$$

where $P_{11}$ is the power spectrum of variable $i$. We will use two definitions of the coherence $R_{4}$, namely,

$$
\begin{aligned}
& { }_{1} R_{i j}=\left[\left\langle C_{i j}{ }^{2}\right\rangle+\left\langle Q_{i j}{ }^{2}\right\rangle\right]^{1 / 2} /\left[P_{i j} \cdot P_{j}\right]^{1 / 2} \\
& { }_{2} R_{i j}=\left[\left\langle C_{i j}\right\rangle^{2}+\left\langle Q_{i j}\right\rangle^{2}\right]^{1 / 2} /\left[P_{i 1} \cdot P_{j j}\right]^{1 / 2}
\end{aligned}
$$

The second is the standard one, while the first is used to circumvent phase aliasing in our repeated profiles due to vertical advection of the variability by internal waves.

\section{PCM Time Series}

In Table 1 we present the station inventory and observation times relative to the beginning of the combined CTD/PCM time series. The sampling interval was 2.5 hours $\pm 35 \mathrm{~min}$ except for the last CTD series (stations 19-1 to 19-5), which were about $20 \mathrm{~min}$ apart. All PCM data have been interpolated into a uniform pressure series with 8-dbar increments by using a three-point parabolic algorithm. Nominally, they start at the 9-dbar pressure level, although the uppermost current records are of low quality hecause of the magnetic influence of the ship's body and surface wave disturbances.

For convenience in presentation. various coordinate transformations and separations of the original depth and timedependent PCM vector $\mathbf{V}^{i}$ have been performed. The stereoperspective 'stick' diagram in Figure 8 shows the ensembleaveraged vertical profile $\left(\mathbf{V}^{\prime i}\right)$ in geographical coordinates.

$$
\begin{gathered}
V^{i}(z, t)=\left[\begin{array}{l}
L^{(i)}(z, t) \\
V^{(i}(z, t)
\end{array}\right] \\
\left\langle\mathbf{V}^{i}\right\rangle=\frac{1}{12} \Sigma V^{i}=\left[\begin{array}{c}
\operatorname{east}(z) \\
\operatorname{north}(z)
\end{array}\right]
\end{gathered}
$$

The surface vector has been calculated from the ship drift, which was monitored by the previously mentioned navigalional buoys. The ship drift during a single lowering was steady, assuring us that the measured variability is real, not induced by a fluctuating coordinate system. Details can be found in the work of Joyce et al. [1976]. 
The profile represents the mean structure of the upper AACC over two inertial periods. It is obvious that the 'mean' current points toward the NNE and that the speed over large portions of the profile is fairly depth independent. Below the seasonal pycnocline the shear values of the averaged components are relatively small $\left(1 \cdot 10^{-4} \mathrm{~s}^{-1}\right.$ for the east, $-5 \cdot 10^{-4}$ $\mathrm{s}^{-1}$ for the north).

In a second step we have rotated the coordinate system, obtaining a front parallel $U_{\|}(z, t)$ and a front normal $V_{1}(z, t)$ set of components. The rotation angle $\left(+73^{\circ}\right.$ from the east) was determined by requiring the averaged cross-frontal component in the interleaving range $(p>249 \mathrm{dbar})$ to vanish $\left(V_{q}\right.$ $=0$ ). Thus

$$
\mathrm{V}^{\mathrm{rot}}=\left[\begin{array}{l}
U_{\| 1} \\
V_{\downarrow}
\end{array}\right]=\left[\begin{array}{c}
U_{q}+U(z)+U(t)+U^{\prime}(z, t) \\
V_{q}+V(z)+V^{\prime}(t)+V^{\prime}(z, t)
\end{array}\right]
$$

The averaged speed of the AACC $U_{a}$ in the depth range covered by our PCM observations yielded $36.1 \mathrm{~cm} / \mathrm{s}$. This value is directly comparable with the findings of Voorhis, who, using neutrally buoyant floats, obtained a 3-day average at $410-\mathrm{m}$ depth of $37.0 \mathrm{~cm} / \mathrm{s}$ toward the NNE as well [Joyce et al., 1976].
A comparison of the $\left(U, V_{1}\right)$ coordinates with the geographical direction of our CTD section shows that crossfrontal direction for the CTD series differed by only $19^{\circ}$. Taking the criterion $V_{q}=0$ as a reference, this small difference in direction may explain the slight tilt of the front parallel sections given in Figure 7 and Figure $A 2$ on the left side. Orientation of the CTD section was determined from earlier XBT crossings of the front. In view of the cyclogenesis occurring (Figure 3), the agreement between the two methods is remarkable. Also the shear $\bar{U}(z)$ closely matches that calculated geostrophically $\left(1.5 \times 10^{-4} \mathrm{~s}^{-1}\right)$ from the horizontal density slope mentioned earlier.

The current fluctuations $U^{\prime}$ and $V^{\prime \prime}$ have been separated from their vertical means $U$ and $V$. All data are shown in comprehensive form in Figure 9. The highest shear values $\left(10^{-2}\right.$ $\mathrm{s}^{-1}$ ) in both components appear in the mixed layer area. Because of the above-mentioned near-surface problem with the PCM they have been neglected for further analysis. More typical shear values, appearing in individual profiles, are of the order of $10^{-2.0}-10^{-3.3} \mathrm{~s}^{-1}$.

While the averaged data showed clear barotropic behavior, we find indications of baroclinicity in the isotachs of the fluctuations during the second half of our observation period. The

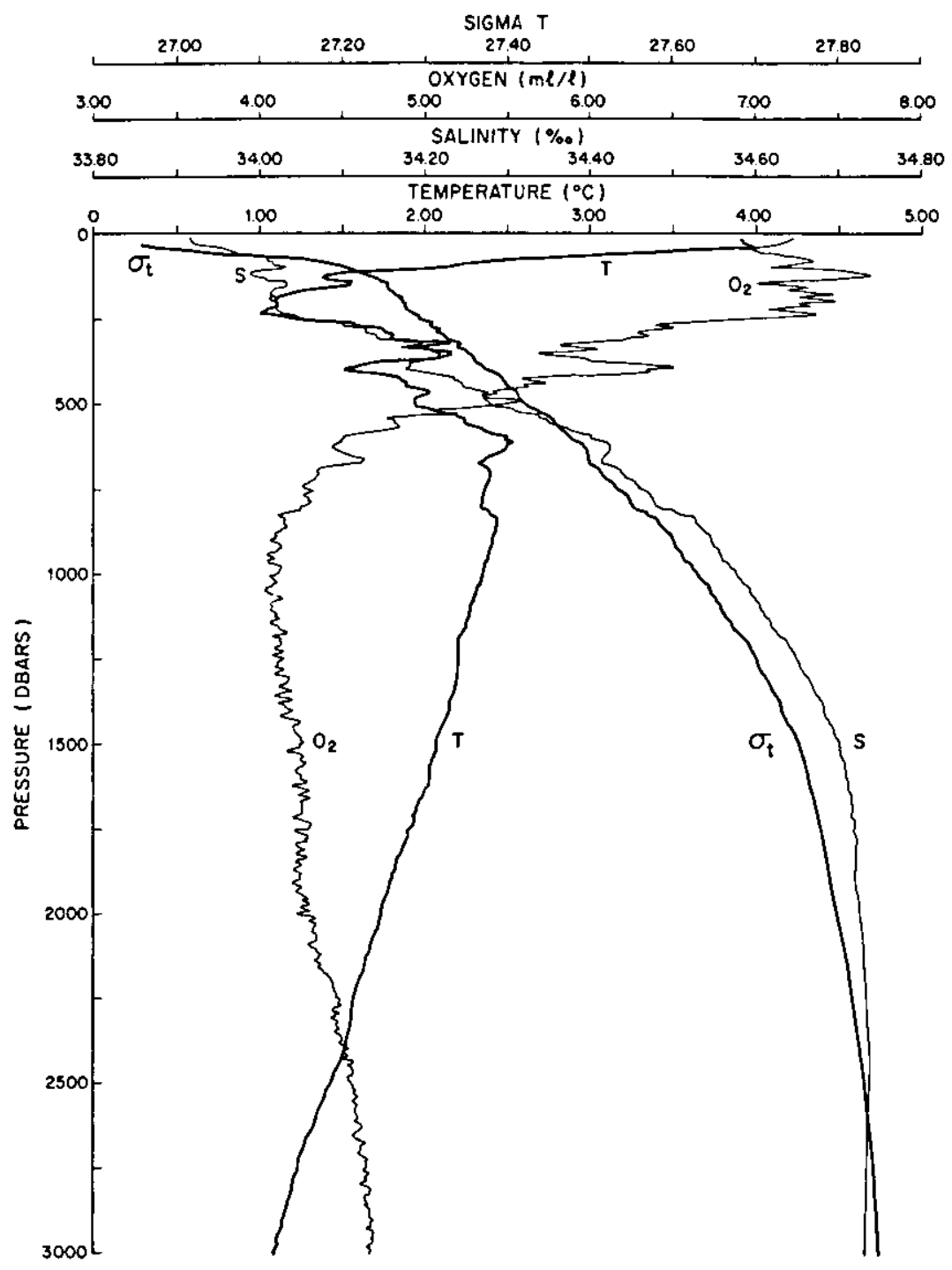

Fig. 6. Profiles of $T, S, \mathrm{O}_{2}$, and $\sigma_{t}$ versus pressure for station 26 . 


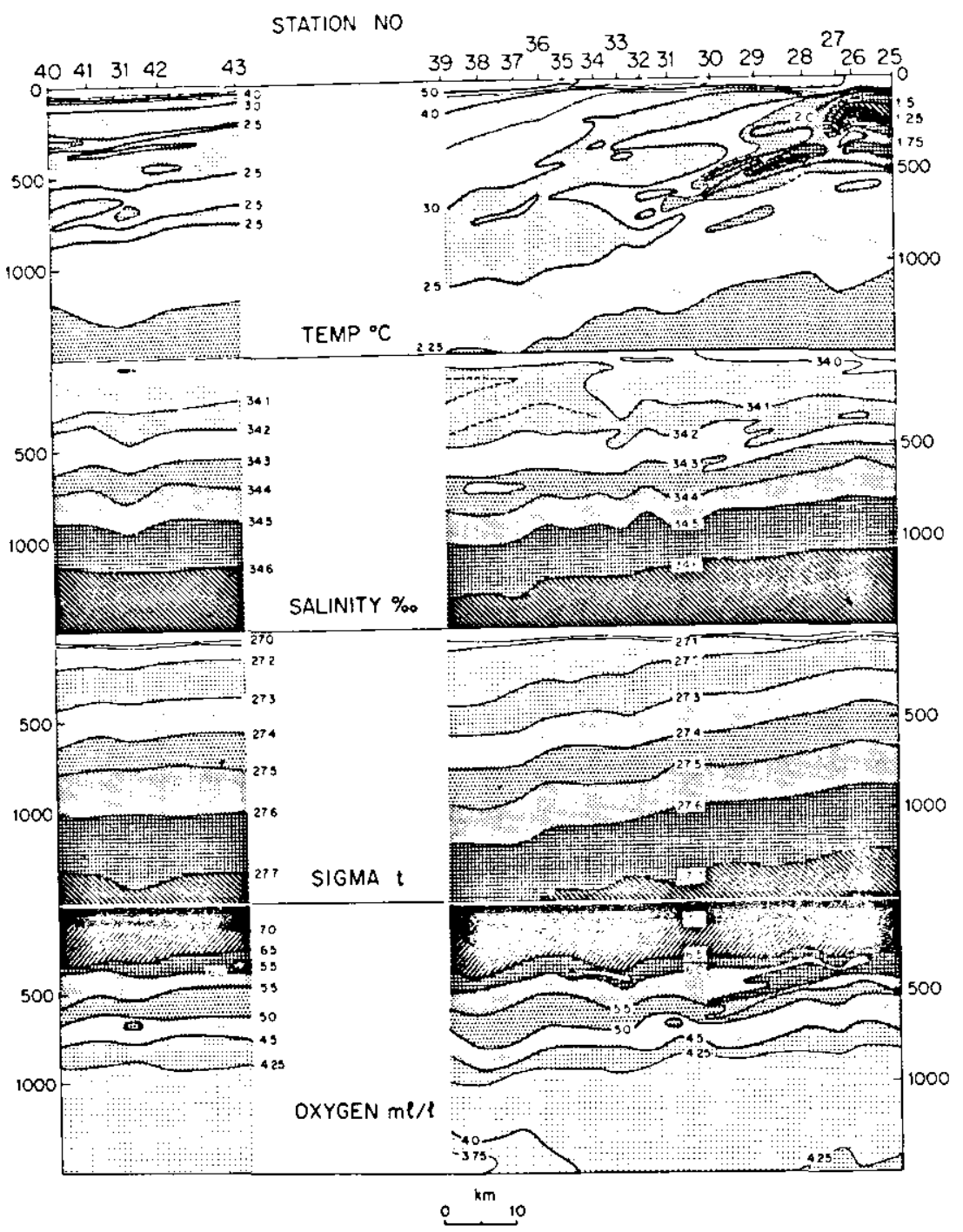

Fig. 7. Sections of temperature, salinity, $\sigma_{i}$, and oxygen from the close-spaced CTD section perpendicular to (right column) and parallel to (left column) the polar front.

present data series, however, is too short to separate the semidiurnal tide and inertial oscillations, although both of these low internal wave frequencies are clearly dominant in the time series. Closer examination of Figure 9 will disclose the counterclockwise turning of the current vector with time which is characteristic of near-inertial oscillations.

The 12 fluctuation profiles $U^{\prime \prime}$ and $V^{\prime}$ have been divided into three overlapping pieces and spectral analyzed in wave number space for the pressure intervals 105 and $561 \mathrm{dbar}$, i.e., beneath

TABLE 1. Elapsed Tine Between PCM Profiles

\begin{tabular}{cc}
\hline Profile & Time $t-t_{0}$, hours \\
\hline 3 & initial CUT time $t_{0}:$ March 1976,2125 \\
4 & 3.0 \\
5 & 5.2 \\
6 & 7.6 \\
8 & 10.9 \\
9 & 13.0 \\
10 & 15.6 \\
11 & 17.8 \\
12 & 20.1 \\
13 & 22.1 \\
14 & 23.9 \\
15 & 26.4 \\
\hline
\end{tabular}

the critical edge of the thermocline. Because of the restricted number of available PCM data, only one interval covering 456 dbar was chosen in favor of higher statistical significance. This is in contrast to the CTD data presented in the next section, which allowed a more detailed analysis. The ensemble and piece-averaged spectral components $P_{C V}$ and $P_{V V}$ are depicted in Figure 10. (Henceforth we skip the primes in the superscripts.) They both represent red spectra and show no significant differences in their slopes $(-2.4)$ and energy levels. The slight change in slopes seen near $10^{-2} \mathrm{cP}$ dbar is probably caused by an artificial effect of the applied Hanning filter. Because of the obvious isotropy of horizontal current fluctuations a further decomposition was made to look for vertical propagation of internal-inertial wave energy through the inspected water column. Spectra were calculated for the same data set as that used for Figure 10 after a decomposition in terms of 'clockwise' (CW) and 'anticlock wise' (ACW) velocity fluctuations with increasing pressure. We note that in both spectra the total horizontal kinetic energy must be the same, since this quantity is invariant under coordinate rotation. $P_{C W}$ and $P_{A C W}$ are comparable in their levels at all wave numbers. Following Leaman and Sanford's [1975] PCM analysis from Mode, this result is indicative of zero net vertical energy propagation during the total observation period. The spectral components were also inspected for shorter-time ensemble aver- 


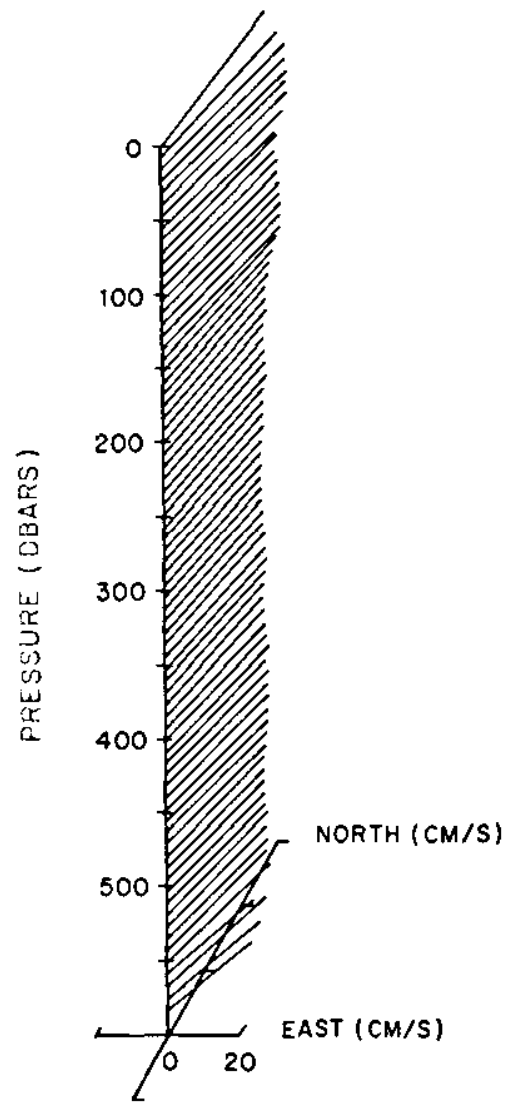

Fig. 8. A perspective diagram of the time mean horizontal velocity versus pressure at the sile of the combined CTD-PCM time series.

ages, showing $P_{\mathrm{CW}}<P_{\mathrm{ACw}}$ at low wave numbers during the first half of the combined CTD/PCM time series. The data base, however, is far too short to conclude from this asymmetry a downward-directed energy flux as was found by Leaman and Sanford for the deep Sargasso Sea. The difference more likely indicates nonstationarity in our time series.

The temporal persistence of the horizontal current fluctuations has been studied by calculating 'dropped-lagged rotary coherence' (DLRC). The vertical wave number spectrum was divided into two bands (band 1: 100-300 dbar, band 2: 30-100 dbar). To improve statistical significance, only time lags smaller than 16 hours were used, so that the cross spectra include at least four estimates per lag and wave number band. Confidence limits were calculated under the assumption that each cross spectrum within the same 2 -hour time lag bin was independent.

Phase angles were plotted in Figure 11 only when they were connected with a significant coherence. In general, the DLRC shows low coherence in both wave number bands. The decrease in coherence at small time lags is consistent with the temperature DLC analysis. The PCM data show a significant rise in coherence at $8 \pm 1$ hours, or roughly one-half an inertial period. Concurrent with this high coherence, the phase is near $180^{\circ}$.

It appears, then, that the fuctuations of the horizontal velocity can be ascribed to internal waves. Formal consistency checks (especially in polar coordinates) are involved and are beyond the scope of this paper.

\section{CTD Time Series}

In Table 2 we list the stations used and the observation time relative to the beginning of the CTD time series. The sampling interval was nominally 2.5 hours except for the last series
(CTD station 19, lowerings 1-5), which were about 20 min apart. In order not to temporally bias our means, the last five profiles were not included in this calculation. The time means (Figure 12), shown as the heavy lines, are much smoother than any one of the instantaneous profiles (station 8 has been plotted on the same figure). At the location of this series near the northern end of our spatial survey (Figure 3 ). the only remnant of the $T_{m / n}$ layer is visible at a pressure of $650 \mathrm{dbar}$ in Figure 12. The weak salinity minimum at the northern end of the section in Figure 7 appears to be a 'nearly isohaline layer in Figure 12 between 150 and $350 \mathrm{~m}$ with a salinity of $34.15^{\circ} \%$. This feature and its relationship to AAIW will be discussed later. The mean buoyancy frequency, below the layer of seasonal influence, is remarkably constant and nearly a theoretician's dream.' Note that the 2.5-hour sampling interval can be badly aliased by vertical displacements of near-buoyancy frequency internal waves. The difference between the mean and instantancous profiles at pressures exceeding $100 \mathrm{dbar}$ is due to some lateral structure in the $T / S$ field; the fresh, cold layer at $360 \mathrm{dbar}$ has a temperature lower than any in the 'mean' water column. The fluctuations of temperature and salinity about these mean values were obtained by subtracting each instantaneous profile from the means shown, in a manner similar to that used for the horizontal velocities. Two 300-dbar pressure intervals were selected centered on 400 and $700 \mathrm{dbar}$. as it appeared that the fluctuations were not homogeneous with pressure, being larger in the shallower interval. The mean temperature and salinity spectra for both segments for all profiles (Figure 13) have the following characteristics:

1. $P_{T T}, P_{S s}$ are red, $P_{T T}$ having a larger slope than $P_{S s}$.

2. Both spectra have a significant energy-containing peak at 100-dbar wavelength.

3. The 250- to 550-dbar interval is more energetic than the 550- to 850-dbar one.

4. The flattening of all spectra at high wave numbers is consistent with a temperature noise level of $0.9 \mathrm{~m}^{\circ} \mathrm{C}$, which after lag correction and use in the conductivity to salinity algorithm has contaminated the salinity measurement. Tem: perature noise is much more apparent in $P_{S s}$ than in $P_{T T}$.

This last point, together with the first one, will be of some relevance in the next section when we will be looking at spectra of temperature and salinity gradients as inferred from Figure 13.

The temporal persistence of the interleaving temperature fluctuations will be studied by calculating "dropped lagged coherence' (DLC) for different wave number bands, in a manner similar to that used for the horizontal currents. In contrast to the currents, we will make these calculations at both constant pressure and constant potential density surfaces. The bands chosen have wavelength bands (in decibars) given by band $1(100-300)$, band $2(30-75)$, and band $3(10-27)$. These contain most of the temperature variance. Salinity persistence was not treated because of the high coherence of salinity with temperature. For both we will use the coherence estimator $2^{R} i j$ $=\left[\left(C_{i j}\right)^{2}+\left(Q_{j}\right)^{2}\right]^{1 / 2} /\left[P_{i j} P_{j j}\right]^{1 / 2}$. The two results appear in Figure 14.

The DLC calculated in pressure space in Figure 14 shows that except for lags of 1 hour, bands 1 and 2 (and also 3 ) are incoherent. Only the first band is coherent at a lag of 1 hour. This is in agreement with Georgi [1978], who has analyzed rapidly sampled ( $\Delta \tau \sim 5 \mathrm{~min}$ ) XBT profiles from this cruise and STD data from an earlier cruise. In contrast to the previously discussed PCM data and Georgi [1978], we find only marginally significant DLC at half-inertial period time lag at the $10 \%$ significance level. 

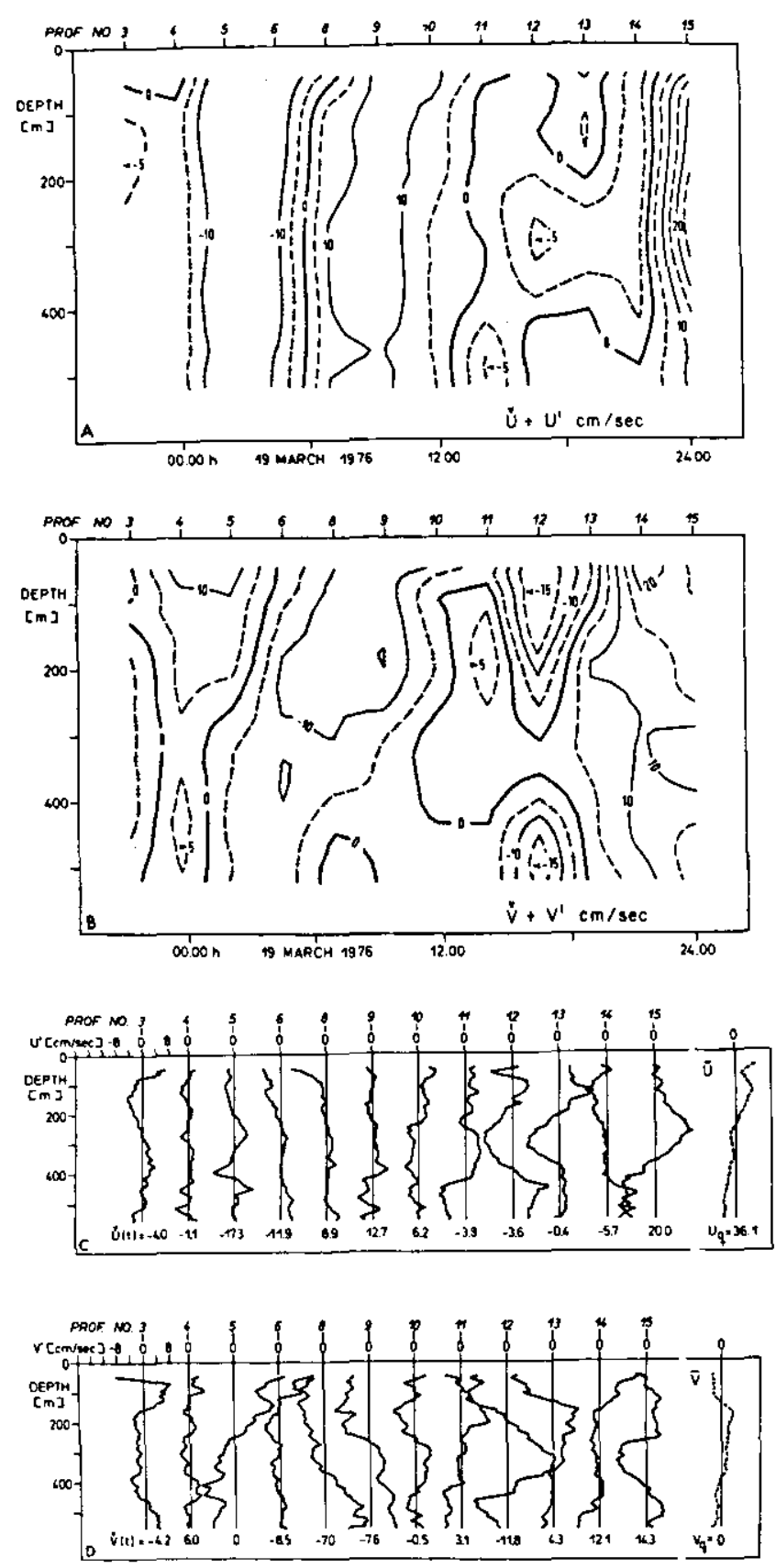

Fig. 9. Refer to (6) in text for current decomposition. In Figures $9 a$ and $9 b$ we show the temporally varying currents $U$ $+U^{\prime}$ and $V+V^{\prime}$, respectively. In Figures $9 c$ and $9 d$ appear profiles of $U^{\prime}, V^{\prime}$. On the far right of Figures $9 c$ and $9 d$ the mean spatial variations about the depth-averaged means $U_{q}, V_{q}$ (i.e., $U, \bar{V}$ are given. Note that by definition, $V_{q}=0$.

When the averaging of $C_{t}, Q_{i}$ was done, it was noted that although individual station pairs with the same time lag had high coherences, the phases differed greatly. Thus when the mean cross spectrum was computed, the individual coherence vectors tended to cancel, leaving a small average coherence estimate. This suggested that the variability was persistent far longer than the DLC calculation implied but that features were advected vertically such that the individual phase estimates for station pairs were random. We have noted earlier that near-buoyancy frequency displacements (sometimes as much as $50-\mathrm{m}$ amplitude from deployed vertical current meters) will cause aliasing and phase randomization. The effect of simple vertical advection can be partially avoided by comput- ing the first coherence estimate in (4), as was done for the PCM data. This method cannot recover coherence losses due to vertical advection out of the sample interval or differential straining of the water column. A procedure was sought to remove both of these effects from the CTD time series.

Since the potential density $\sigma_{\theta}$ of a water parcel is conserved in adiabatic processes, using $\sigma_{\theta}$ as the independent vertical coordinate would remove internal wave displacements and straining. Information is then lost about the vertical excursions of the parcel, and comparison is difficult with previous results where pressure was used as the independent variable. Instead we reassigned the pressure of that parcel by giving it the pressure at which the series mean $\sigma_{\theta}$ equaled the $\sigma_{\theta}$ of the 


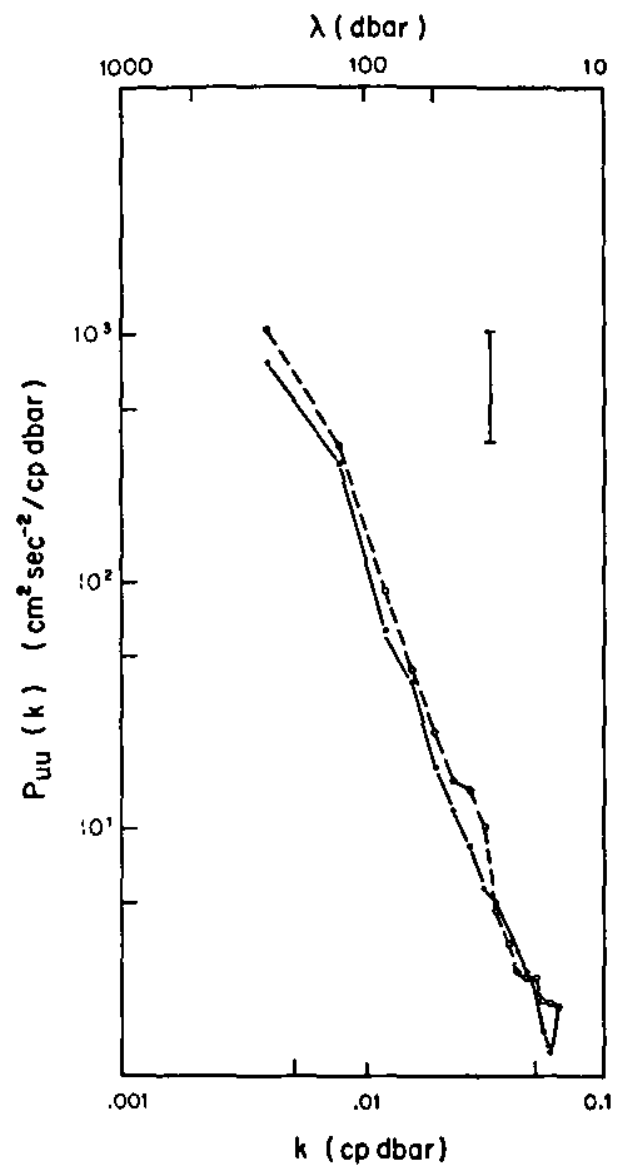

Fig. 10. Spectral decomposition of $U^{*}, V$ in (6). Error bars for $5 \%$ statistical significance are calculated assuming each profile to be independent. Solid and dashed lines denote $P_{v^{\prime} v^{\prime}}$ and $P_{u^{\prime} u^{\prime}}$, respectively. parcel in a manner similar to that of Johnson et al. [1978]. In addition, a new variable is created, parcel displacement, by differencing the parcel and mean pressures.

When this procedure was done point by point, the resulting temperature profiles became asymmetric owing to density fine structure on the scale of the intrusions. So as not to interpret these as internal wave displacements, a 100-dbar boxcar running mean was taken on each instantaneous $\sigma_{\theta}$ profile. More will be said later about the density fine structure.

The final profiles clearly show that features are persistent for much longer than the above DLC calculations would suggest. The mean $T, S$ profiles for the series show a little more structure than before, but they are smooth enough to confirm that the two inertial period series are long enough to resolve the longest coherent time scale in the series. Proceeding as before, we removed the mean profiles from the individual series and computed the average DLC. This time the result (Figure 14, left) shows that the most energetic intrusions were persistent for over 5 hours. There is no significant coherence at 7 hours as before. Upon careful examination of the raw profiles again it was noticed that the dominant temperature features were being advected vertically by an amount comparable to half their vertical wavelength and at a period of $12-14$ hours. This could explain high coherences and phases near $180^{\circ}$ at periods near 7 hours.

Remarkably, the features in band 2, 550-850 dbar are persistent for over 12 hours. More importantly, the phase estimates show a steady deepening of the features over the course of the experiment with the exception of the short 1-hour lag value. Since the vertical coordinate is now in effect potential density, the nonzero phases imply that features cross density surfaces. Rather than attributing this to some local nonisentropic process, we interpret it as advection of sloping features past the measurement point.
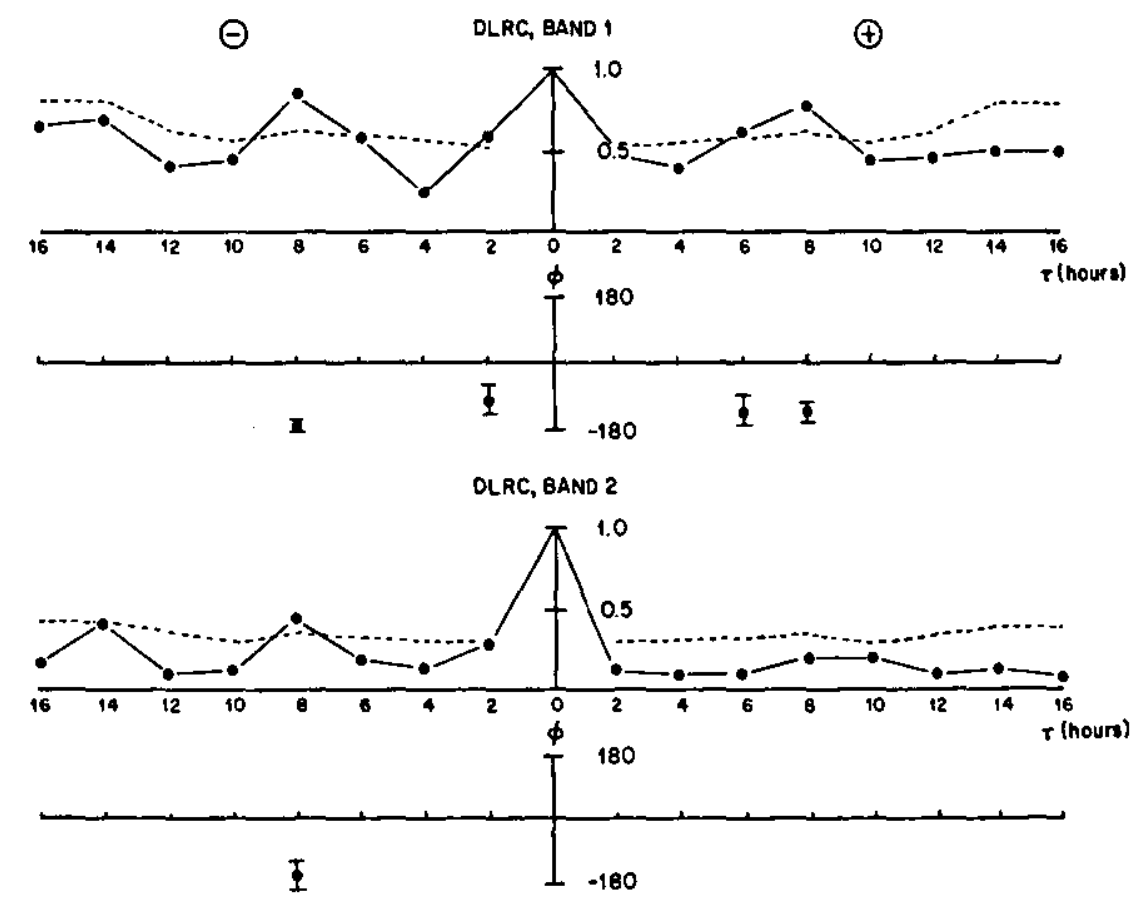

Fig. 11. DLRC results for clockwise (plus) and anticlockwise (minus) velocity fluctuations. Phase estimates are $5 \%$ significance intervals. Band 1 spans wavelengths 128-256 dbar, while band 2 covers 32-82 dbar. 
TABLE 2. Elapsed Time Between CTD Profiles

\begin{tabular}{cc}
\hline Profile & Time $t-t_{0}$, hours \\
\hline 7 & initial CUT time $t_{0}:$ March $8,1976,2022$ \\
8 & 3.62 \\
9 & 2.00 \\
10 & 2.35 \\
11 & 2.47 \\
12 & 2.98 \\
13 & 2.42 \\
14 & 2.52 \\
15 & 2.17 \\
16 & 2.02 \\
17 & 2.18 \\
18 & 2.38 \\
$19-1$ & 2.20 \\
$19-2$ & 0.45 \\
$19-3$ & 0.38 \\
$19-4$ & 0.34 \\
$19-5$ & 0.35 \\
\hline
\end{tabular}

In Figure 15, potential temperature is plotted against stretched pressure for the last five profiles. Not only is the visual coherence large, but also features can be observed to move upward from left to right across the figure. Thus during this period when the cross-frontal flow was most probably northward (Figure 9), features became lighter, i.e., intrusions became shallow faster than density surfaces moving in a poleward direction across the front. The DLC's at lags less than 2 hours were made exclusively with these stations and show positive phase estimates unlike the negative phase estimates at longer lags made from stations taken when the flow was primarily southward. An estimate of the intrusion slopes will be made in the next section.

\section{Discussion}

In comparing the temperature/salinity spectra from the two levels $250-550$ and $550-850$ we found (Figure 13) that the shallower interval was more energetic. This can be explained by the change of lateral water mass structure with depth. In Figure 5 the spreading of the $T / S$ families is greater for waters fresher than $34.20 \%$ than for the saltier, deeper waters. In other words, on a given potential density surface, $T / S$ changes are larger for the 250- to 550-dbar interval (which is fresher than $34.20 \%$ ). The relationship between vertical interleaving and lateral (or isopycnal) water mass variability suggests two different kinematic models for the energetic scaling of intrusions: internal waves and lateral mixing. We will deal first with the possibility that internal waves, by laterally displacing water parcels belonging to different water masses, can cause vertical interleaving. In frequency-wave number space this can be stated

$$
-i \omega \hat{f}(\omega, \kappa)+\hat{V}(\omega, \kappa) \partial_{y} \bar{T}=0
$$

where $\vec{V}$ is the transform of the velocity component perpendicular to the front and $\partial_{y} T$ is the large-scale cross-frontal temperature gradient. The internal wave temperature signal $t$ is then directly proportional to $\partial_{y} T$ :

$$
T=(V / i \omega) \partial_{y} T \leq(V / i f) \partial_{y} \bar{T}
$$

where $f=2 \pi \tau_{l}^{-1}$ is the inertial frequency. If $f$ and $\nu$ are related as above, this demands that (1) their vertical spectra are similarly related and (2) they are $90^{\circ}$ out of phase. Estimating $\partial_{y} \bar{T}$ is difficult, since this represents the horizontal temperature gradient in the absence of intrusions/internal waves. By averaging a number of values from the synoptic picture in Figure 7 we get
TEMPERATURE $\left({ }^{\circ} \mathrm{C}\right)$
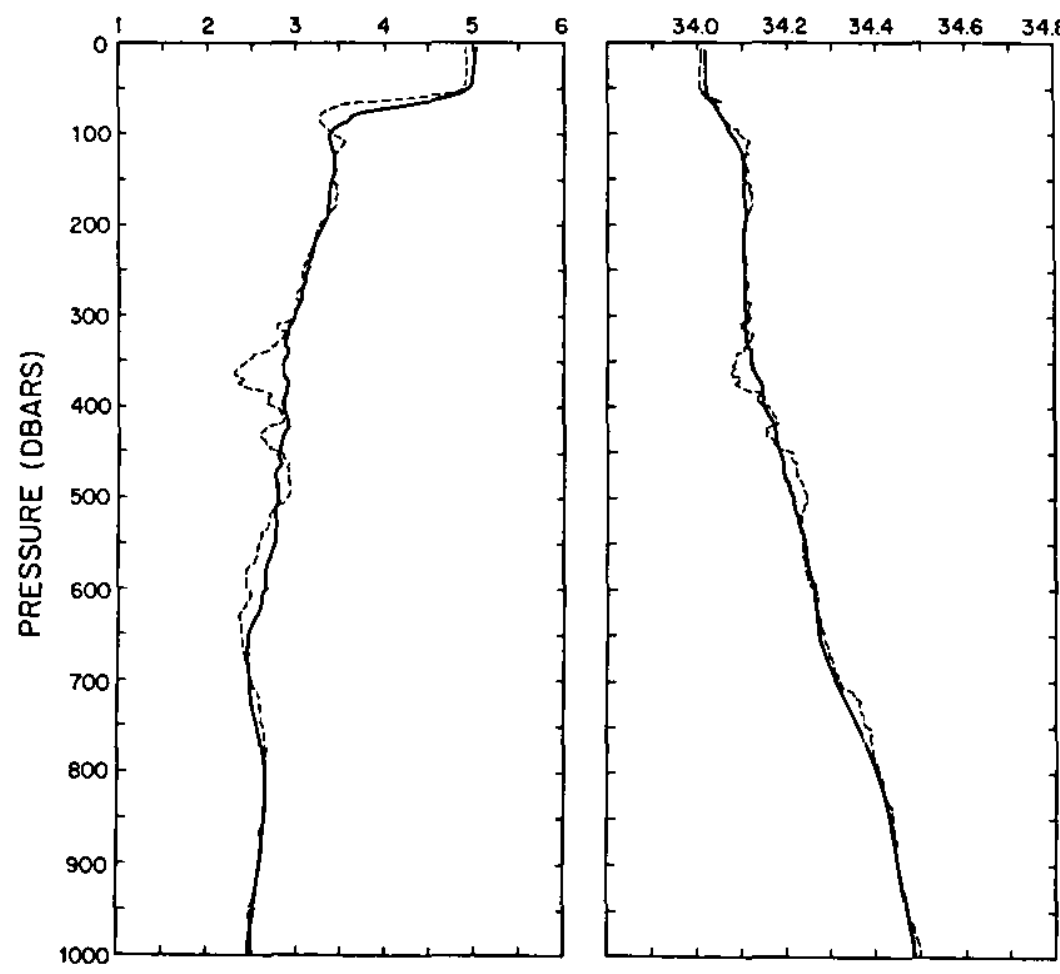

BUOYANCY FREQ. (CPH)

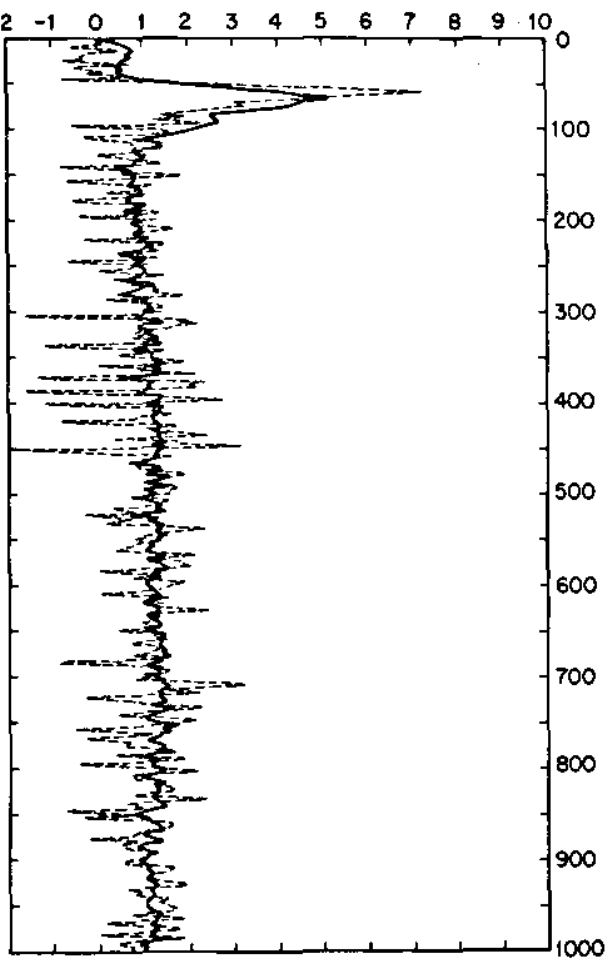

Fig. 12. Time mean (solid curve) profiles of $T, S$, and $N$ versus pressure for CTD time series. Dashed curves for an individual profile (CTD station B) are shown for comparison. 

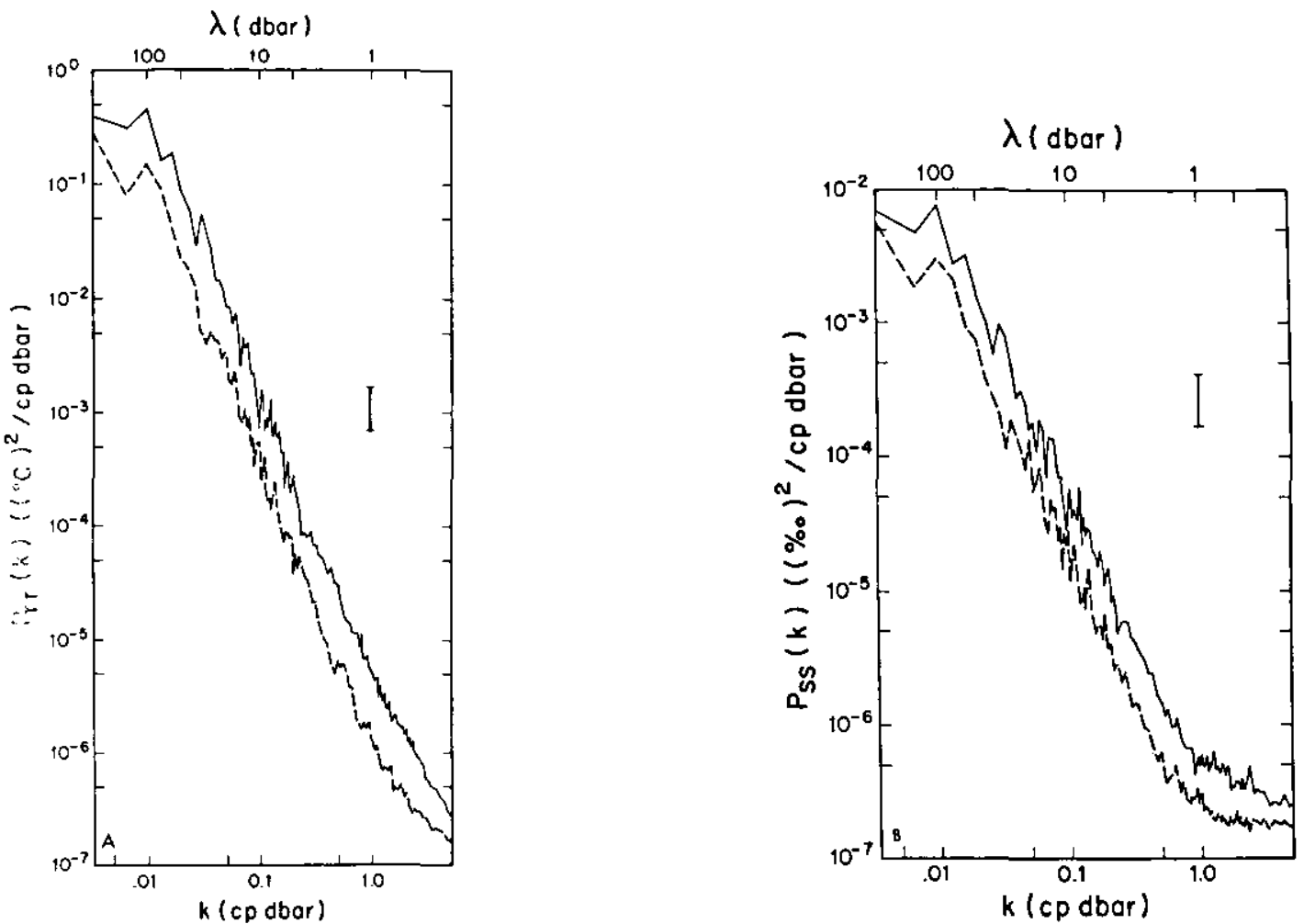

Fig. 13. Ensemble-averaged spectra of $(a)$ temperature and (b) salinity for fluctuations in pressure ranges $250-550 \mathrm{dbar}$ (solid line) and 550-850 dbar (dashed line). Significance intervals of 5\% ( $95 \%$ confidence) are calculated assuming independent profiles.

$$
\partial_{y} \bar{T} \simeq 1^{\circ} \mathrm{C} / 30 \mathrm{~km} \simeq 0.33 \times 10^{-40} \mathrm{C} \mathrm{m}^{-1}
$$

with

$$
f=1.2 \times 10^{-4} \mathrm{~s}^{-1}
$$

and we predict, using the inequality in (8), that

$$
P_{T T^{(k)}} \leq 8 \times 10^{-6}\left({ }^{\circ} \mathrm{C} / \mathrm{cm} \mathrm{s}^{-1}\right)^{2} P_{V V^{i k)}}
$$

Therefore the temperature spectrum should have an upper bound given by $10^{-6}$ times the velocity spectrum. Comparison of $P_{V V}$ in Figure 10 with $P_{T T}$ in Figure 13 shows that $P_{T T}$ is too large by a factor of at least $10^{2}$. (A similar finding was reached in a slightly different way and with other data by Georgi [1978].) It was mentioned that the PCM also measured temperature; an examination of the cross spectrum $\Gamma_{V r}$ showed that $C_{V T}, Q_{v T}$ were of comparable size and that the coherence between the two was not statistically significant. Thus we rule out internal waves as the primary source of the interleaving, though they may (and do) play some role in the polar front data.

One such role is the production of turbulent kinetic energy, necessary for mixing processes in the interleaving range. An important parameter in this regard is the instantaneous gradient Richardson number, $R i$. In Figure $16 a$ a scatter plot of vector shear of the individual PCM drops for pressure values greater than 250 dbar against the corresponding averaged buoyancy from the CTD time series is presented. Because of the time lag of approximately $30 \mathrm{~min}$ between the CTD and the PCM cast, we have preferred the ensemble-averaged $N$ data, calculated from the surrounding current observation levels \pm 3 dbar. The stretched cloud is bounded on the $N$ axis by 0.83 and $1.41 \mathrm{cph}$, values which coincide with Figure $12 c$. Though the bulk of points seems to demonstrate stability, it was found that $15 \%$ lie below $R i=1$ and $5 \%$ below $R i=0.25$, hence providing possible sites for mechanical mixing due to shear instability. Our data must underestimate the actual situation in situ because of the restricted instrumental capabilities $\left(P_{\min }=8 \mathrm{dbar}\right)$. The greater scatter of points in Figure $16 \mathrm{~b}$ may be indicative of synoptic errors between $N$ and $S$ rather than more vigorous mechanical mixing.

Another strong candidate for vertical exchanges within the polar front is double diffusion due to differing molecular heat and salt diffusivities.

Because of the large inversions of temperature and salinity this process could be more effective in fronts than shear instability of internal waves. Interleaving enhances lateral mixing for either mechanism, as was pointed out in a model of lateral water mass exchange by Joyce [1977].

The model states that in order to maintain a statistically steady state of interleaving temperature and salinity fields in the presence of small-scale dissipation, fluxes of heat and salt must be supplied. The interleaving scale acts as an intermediary in this process, enhancing the lateral exchange by offering a large surface area of contact between the differing water masses. The fact that interleaving also provides vertical inversions in the instantaneous $T / S$ profiles permits smallscale vertical transfers by double-diffusive mechanisms. This added bonus will enhance the lateral exchange. If the smallscale vertical mixing of $T / S$ can be characterized by effective diffusivities $\tilde{A}_{T}{ }^{V} / \tilde{A}_{S}{ }^{v}$, then the lateral fluxes of temperature and salinity across the front can be written following Joyce [1977]:

$$
\begin{aligned}
& F_{T}=\text { temperature flux }=\overline{\bar{A}_{T}^{v}\left(\partial_{2} \tilde{T}\right)^{2}} /\left(\partial_{y} \tilde{T}\right) \\
& F_{S}=\text { salinity flux }=\overline{\tilde{A}_{S}^{v}\left(\partial_{2} \tilde{S}^{2}\right.} /\left(\partial_{y} S\right) \\
& F_{\rho}=\text { buoyancy flux }=-\alpha \rho_{0} F_{T}+\beta \rho_{0} F_{S}
\end{aligned}
$$



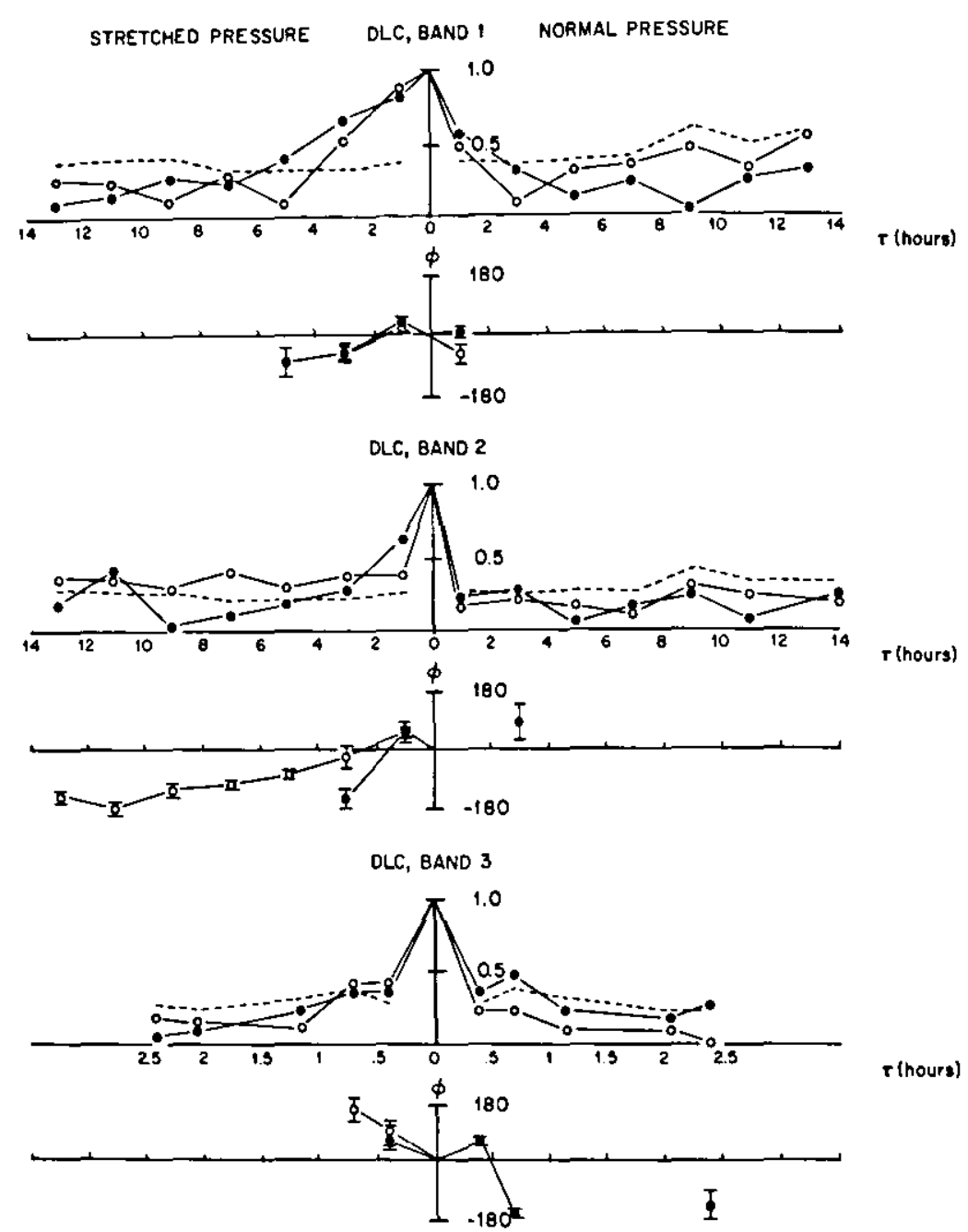

Fig. 14. DLC for three bands of temperature variability versus pressure (right) and stretched pressure (left). Bands 1-3 are 300-100 dbar, 75-30 dbar, and 27-10 dbar, respectively. Phase estimates are given for coherences above the 5\% significance level (dashed line).

In (11) the tilde and the overbar refer to averages over the interleaving (medium) and large-scale fields, respectively, $\tilde{A}_{T}{ }^{V}$, $\vec{A}_{s}{ }^{V}$ are the small-scale diffusivities acting on the intrusions, $y$ is a direction normal to the front, and $\alpha, \beta$ are the coefficients of volume expansion for heat and salt, respectively. Since the amplitude of the intruding salinity $S$ can determine if in the large scale salinity increases with depth or if inversions can occur (see Figure 12), it is conceivable that $\dot{A}_{T}{ }^{\nu}$ and $\bar{A}_{S}^{T}$ are complicated functions of the larger scales. However, we will take them to be constants. We will also associate the largescale average (overbar) with the ensemble average (angle brackets) in order to perform the calculations of (11). This means physically that the intrusion scales will be defined by the difference between an instantaneous and ensemble mean profile. Recall that this decomposition produced the spectra of Figure 13.

The temperature, salinity, and buoyancy fluxes can now be rewritten

$$
\begin{gathered}
F_{T} \equiv-\langle\bar{V} T)=A_{T}{ }^{v}\left\langle\left(\partial_{z} \tilde{T}\right)^{2}\right) / \partial_{y} \bar{T} \\
F_{S} \equiv-\langle\mathcal{V} S\rangle=A_{S}{ }^{v}\left(\left(\partial_{z} S\right)^{2}\right\rangle / \partial_{y} \bar{S} \\
F_{\rho} \equiv-\langle V \bar{\rho}\rangle=\rho_{0} \beta F_{S}\left[1-\left(A_{T}{ }^{v} / A_{S}{ }^{\nu}\right)\right. \\
\left.\cdot\left(\beta \partial_{y} S / \alpha \partial_{y} T\right)(\alpha / \beta)^{2}\left\langle\left(\partial_{z} T\right)^{2}\right\rangle /\left\langle\left(\partial_{z} S\right)^{2}\right\rangle\right]
\end{gathered}
$$

In the previous section we noted that the temperature and salinity spectra were both red but not equally so. It can be seen above that this will be important in the calculation of $F_{\rho}$. The temperature and salinity gradient spectra for the 250. to 550-dbar interval appear in Figure 17 together with the coherence, phase, and the mixing ratio

$$
(\alpha / \beta) \cdot\left(P_{T_{s} T_{v}} / P_{s_{s},}\right)^{1 / 2}
$$

At wave numbers above 1 cycle/dbar the $T / S$ variability is correlated because the salinities are contaminated by thermal noise, as is discussed in more detail by Joyce [1976b]. The natural variability in temperature is such that the noise level is not reached until the Nyquist wave number, 5 cycles/dbar. Thus temperature gradient spectra may be used nearly to the Nyquist scale, whereas salinity gradients are unreliable beyond 0.5 cycle/dbar. Long before this limit is reached, however, $P_{S_{S_{2}} s_{2}}$ can be seen to be flatter than $P_{T_{2} T_{2}}$. The mixing ratio defined above shows this more clearly, tending downward below unity at wave numbers as large as 0.05 cycle/dbar. It was noted that previous workers [Gordon et al., 1977] had reported intrusions to be 'density compensating.' This would mean a mixing ratio of 1 in spectral terms. We see from the figure that at the largest scales, which contain most of the $T / S$ variance, this is true. As lateral exchanges depend upon vertical gradients of $T / S$, one can see that the smaller scales play a crucial role. 


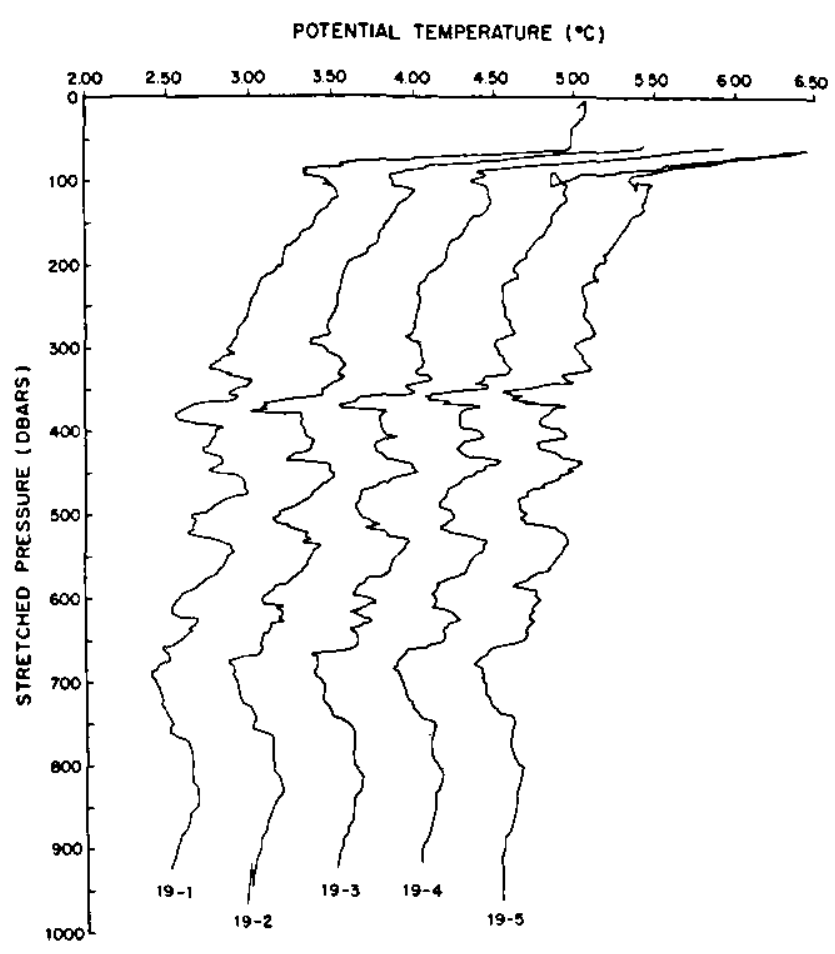

Fig. 15. Profiles of potential temperature versus stretched pressure for CTD station 19, lowerings 1-5. Time separation between stations (about $20 \mathrm{~min}$ ) is given in Table 2 . Successive profiles after station 19.1 are offset $0.5^{\circ} \mathrm{C}$.

The temperature gradient spectrum in Figure 17 shows a peak at the dominant interleaving scale of $0.01(\mathrm{dbar})^{-1}$ and a slope change at $0.3(\mathrm{dbar})^{-1}$. We suggest that beyond this wave number, vertical mixing is dominating $P_{T_{2} T_{2}}$ and we are beginning to see, but not resolve, a different physical process. Using $3 \mathrm{dbar}$ as the smallest wavelength of interleaving, $A_{T}{ }^{v}=A_{S}{ }^{v} \simeq$ $1 \mathrm{~cm}^{2} \mathrm{~s}^{-1}$, and $\partial_{y} \bar{T}=0.33 \times 10^{-4}{ }^{\circ} \mathrm{C} \mathrm{m}^{-1}$, we estimate

$$
F_{H} \equiv-\langle\tilde{v} T)=0.065^{\circ} \mathrm{C} \mathrm{cm} \mathrm{s}^{-1}
$$

This corresponds to a horizontal heat diffusivity of

$$
A_{T^{H}}{ }^{H}=2 \times 10^{\mathrm{s}} \mathrm{cm}^{2} \mathrm{~s}^{-1}
$$

(as opposed to the heat flux along a density surface calculated below).

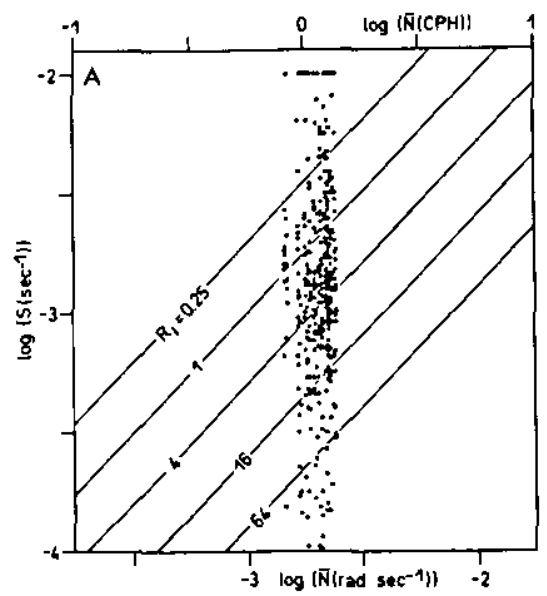

These estimates are crude insofar as the small-scale mixing efficiency is unknown. A value of $1 \mathrm{~cm}^{2} \mathrm{~s}^{-1}$ was chosen for the small-scale heat and salt diffusivity. Gorrett [1977] has recently reviewed mixing in the ocean interior and points out that not enough is known about the energetics of either internal waves or double diffusion to be able to estimate their effect upon larger scales in terms of vertical diffusivities. Our value represents a harmonic mean between low central gyre values and high values from salt fingering regimes. One might ask whether the PCM could have directly measured the heat flux $\langle-i t\rangle$ with the diffusivities then deduced from the model. Using the observed temperature and velocity variability and the above heat flux, we predict a correlation coefficient of 0.08 , well below our significance level for the PCM cross-spectral coherence. Thus the direct method cannot be used with the present data.

The above heat flux estimate is comparable to the estimates of Bryden [1978], who used long time series of moored current meter data from the polar front at depths below $1000 \mathrm{dbar}$. At these large depths, however, interleaving is insignificant, and therefore Bryden's fluxes cannot be largely attributable to the process we are discussing. Because of the tight $T / S$ relation the deeper moored current meter results could be translated into buoyancy fluxes and were consistent with available potential energy release or down-gradient flux of buoyancy. We will now show that based on our model and the combined temperature and salinity fluxes, the flux of buoyancy is up gradient!

From Figure 7 it can be seen that the horizontal salinity gradient in the upper $500 \mathrm{~m}$ is small and difficult to estimate. Given the horizontal temperature and density gradients, a less noisy estimate of $\partial_{y} S$ can be made. Instead, we will orient our coordinate system along density surfaces so that $y, z$ now are along and normal to this new coordinate system.

For

$$
\begin{aligned}
\partial_{y} \bar{T} & =0.25 \times 10^{-1} \quad{ }^{\circ} \mathrm{C} \mathrm{m}^{-1} \\
\alpha & \left.=95 \times 10^{-8} \quad\left({ }^{\circ} \mathrm{C}\right)^{-1}\right] \\
\beta & =772 \times 10^{-8} \quad(\% o)^{-1}
\end{aligned}
$$

we get

$$
\begin{aligned}
\partial_{y} S & =0.31 \times 10^{-6} \% \mathrm{~m}^{-1} \\
F_{\rho} & =\rho_{0} \beta F_{S}\left[1-0.015\left\langle\left(\partial_{z} T\right)^{2}\right\rangle /\left(\left(\partial_{2} S\right)^{2}\right\rangle\right]
\end{aligned}
$$

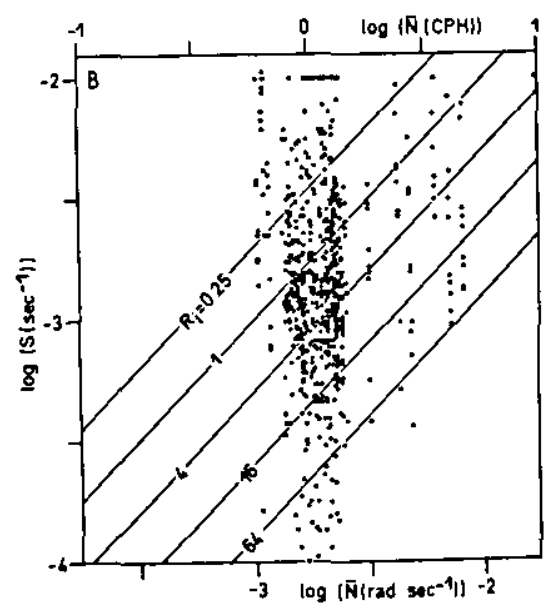

Fig. 16. Scatter plot of shear $\left[\log _{10}\left(u_{z}^{2}+v_{z}^{2}\right)^{1 / 2}\right]$ versus mean $\left(\log _{10} N\right)$ buoyancy frequency at the same pressure for PCM data in the time series. Lines of constant Richardson number $R i$ appear as straight lines. 

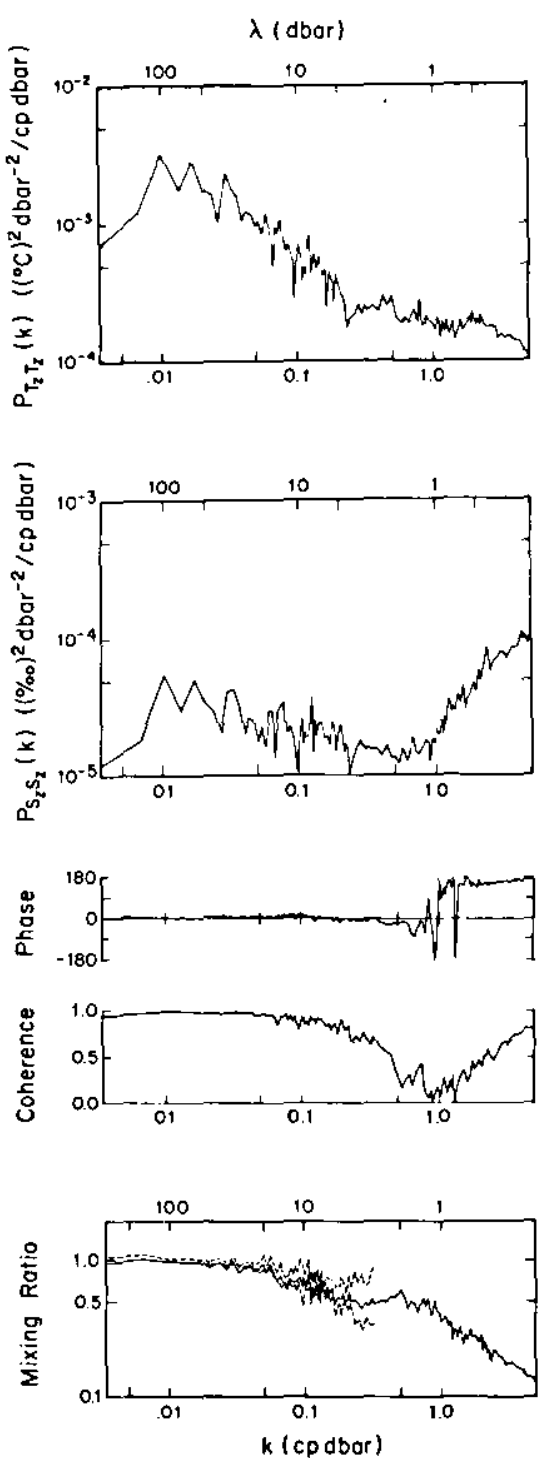

Fig. 17. Ensemble-averaged gradient spectra for 250- to 550-pressure interval. Shown are spectra of temperature gradient, salinity gradient, coherence, phase, and mixing ratio. The last quantity from (13) is plotted with error bounds.

The ratio $\left\langle\left(\partial_{2} T\right)^{2}\right\rangle /\left(\left(\partial_{2} S\right)^{2}\right\rangle$ can be bounded below and above by regression parameters which assume all noise to be in temperature or salinity, respectively. We obtain

$$
F_{\rho}=\rho_{0} \beta F_{s}(0.38,0.59,0.72)
$$

Even the largest estimate of the above ratio is not sufficient to change the sign of $F_{\rho}$, which is in the same direction as $F_{s}$.

Using (12) suitably rotated we obtain the following positive poleward fluxes:

$$
\begin{aligned}
F_{T} & =0.086 \quad{ }^{\circ} \mathrm{C} \mathrm{cm} \mathrm{s}^{-1} \\
F_{S} & =0.069 \% \mathrm{~cm} \mathrm{~s}^{-1} \\
F_{p} & =2 \times 10^{-6} \mathrm{~g} \mathrm{~cm}^{-2} \mathrm{~s}^{-1}
\end{aligned}
$$

where we have used the most conservative estimate for the buoyancy flux. Obviously, some assumption is wrong if we get a buoyancy flux along density surfaces. This coordinate system was chosen because (1) it permitted more reliable estimates of horizontal salinity gradients and (2) it seemed the proper coordinate system for looking at mixing which conserved potential density. From application of the model it would appear that mixing does not conserve potential density and that interleaving tends to enhance the existing horizontal density gradient.

The above analysis is highly model dependent and treats only the consequences and not the dynamics of interleaving; it is therefore open to criticism. The smallest scale of interleaving is tenuous as are the magnitudes and in fact the correctness of the constant vertical heat and salt diffusivities. As noted by Joyce [1977] a range in the latter from 0.5 to $5 \mathrm{~cm}^{2} \mathrm{~s}^{-1}$ gave a comparable order of magnitude spread in all subsequent results, independent of noise considerations. Two additional factors, however, support our model results.

The first of these was mentioned in the last section: namely, intrusions do not conserve potential density as they 'move' across the front. This motion is most probably small, being masked by the AACC and internal waves. That it exists is inferred from the fact that intruding features can be traced across the front some few kilometers, the cold (warm) layers appearing to get denser (lighter) as they move equatorward (poleward).

Although no direct measurements were made of the slope of small intrusions relative to large-scale density surfaces, slopes can be computed from the time series by using the combined CTD and PCM data. The depth-averaged, time-dependent, cross-frontal velocity $V(t)$ was used to obtain an estimate of the relative displacement undergone by the water between CTD casts. For each pair of CTD temperature anomaly profiles (versus stretched pressure) the phase angle between the profiles was plotted, for each of the first two wave number bands, against cross-frontal displacement. In Figure 18 we show the results for the two bands together with regression lines where the independent variable is displacement (solid line) and phase (dashed line). The PCM measurements ended before the rapidly sampled CTD series (stations 19-1 to 19-5) so the relative displacements for CTD pairs using these stations are obtained by linear extrapolation. Extrapolated data appear as open symbols in the figure and were not used to obtain the regression lines. Note also that the $360^{\circ}$ phase uncertainty has been used in some cases to shift data when it appeared reasonable to do so in order to get a consistent picture.

The results of Figure 18 strongly support the conclusion that intrusions slope relative to density surfaces. The slope $m$ can be expressed in terms of the vertical wave number $\alpha$ and the standard deviation of the phase $\sigma_{\phi}$ and the displacement $\sigma_{Y}$ by

$$
m=\left(\sigma_{\phi} / \sigma_{Y}\right) \kappa^{-1}
$$

This estimate can be bounded above and below with the slopes for the two regression lines. Using a vertical wavelength of 100 $\mathrm{m}$ and $75 \mathrm{~m}$ for bands 1 and 2, respectively, we obtain

Band 1

$$
m=-0.012,-0.028,-0.062
$$

Band 2

$$
m=-0.020,-0.024,-0.029
$$

These slopes are 3-4 times the slope of the density surfaces (second section) and are in the sense of cold (warm) intrusions deepening (shallowing) across density surfaces to the north (south). 


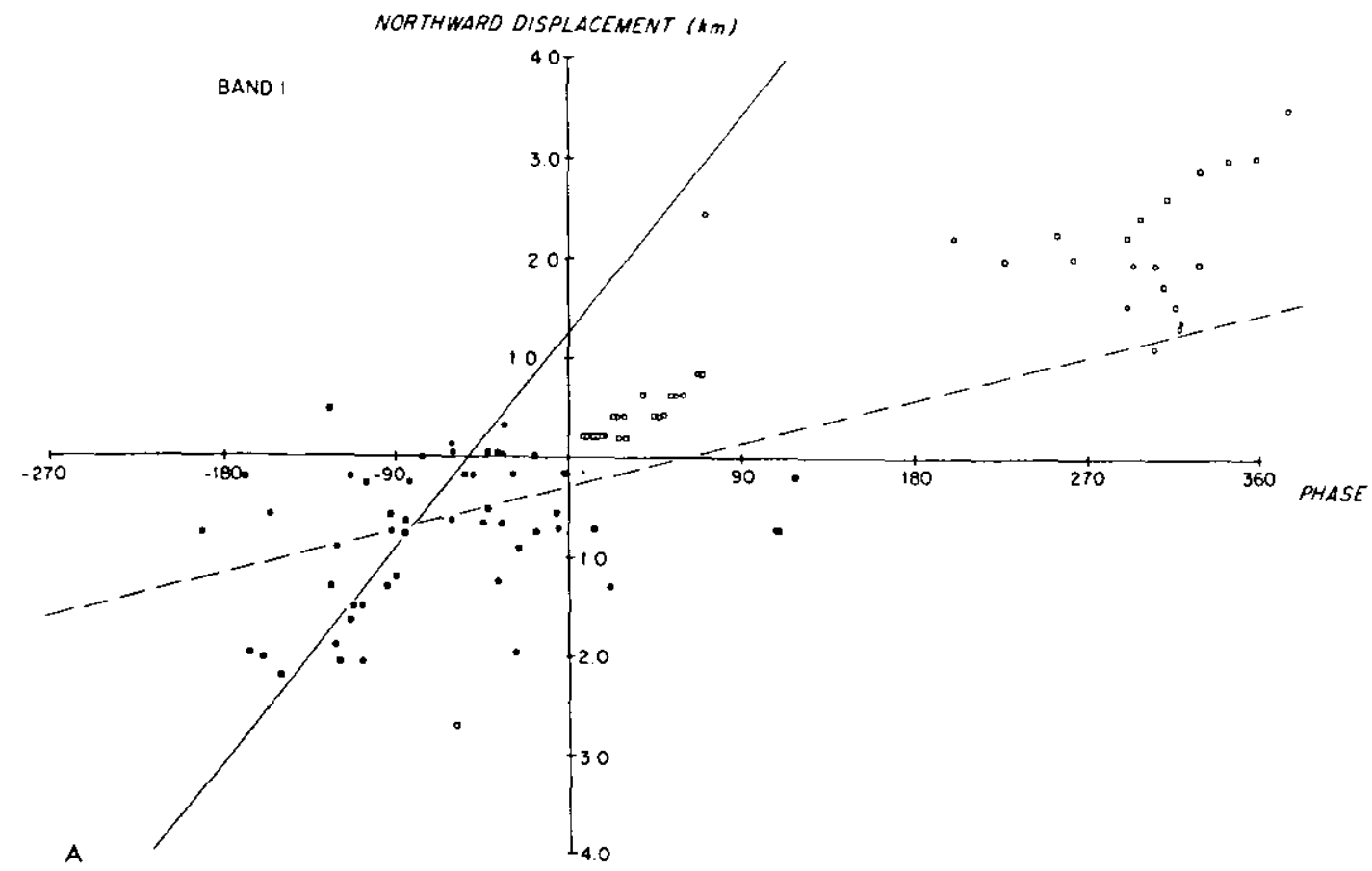

Fig. 18a. Scatter plot of cross-frontal displacement between pairs of CTD casts against phase angle between the potential temperature anomaly features of those stations in isentropic coordinates for band 1 ( $300-100 \mathrm{dbar})$. Data from the shallower pressure interval (250-5.50 dbar) are denoted by circles, while squares mark the deeper range (5.50-850 dbar). Linear regression lines for the distribution (see text) are shown.

If double-diffusive processes are active in the polar front, salt fingering is occurring below warm, salty intrusions and over stable convection above. Laboratory studies by Turner [see Turner, 1973] showed that salt fingers can remove buoyancy more effectively than their convective counterparts. Thus warm salty layers will get fresher, and cold fresh ones will become more salty and sink. Nonrotating laboratory experiments by Turner [1978] have confirmed this. Furthermore, the initial density gradient will be enhanced by the convection and reduced by the fingering. giving a signature of high stability above warm salty layers and low stability below. In the interleaving region between 200 and $700 \mathrm{dbar}$ (Figure 12) the mean temperature gradient is about $0.001{ }^{\circ} \mathrm{C} \mathrm{m}^{-1}$. For one of the CTD profiles in this region (station 19-4) we have looked at the stability (computing buoyancy frequency with data decimated at 2-dbar increments) when the temperature gradient

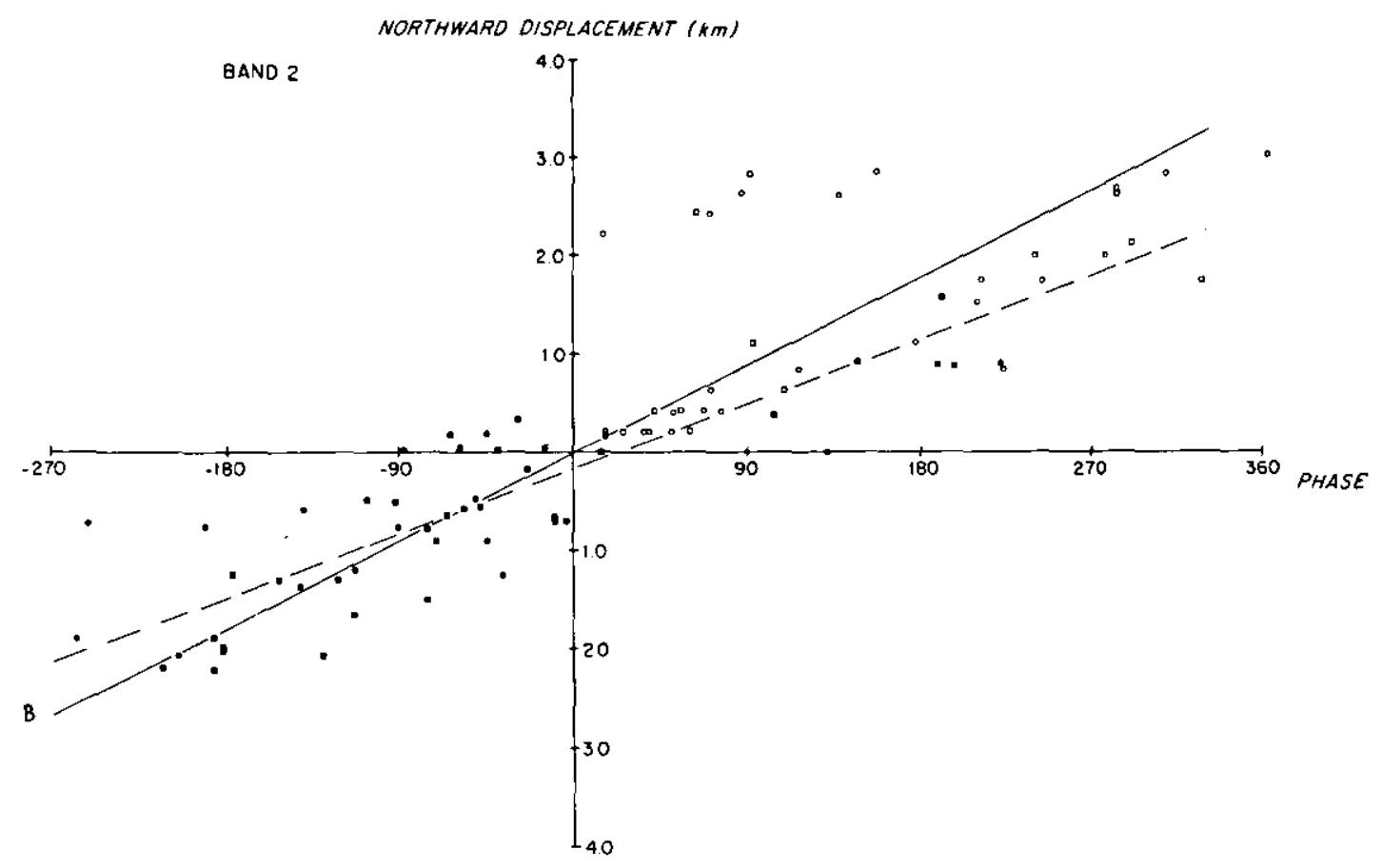

Fig. 18b. Same as Figure $18 a$ but for band 2 (75-30 dbar). 

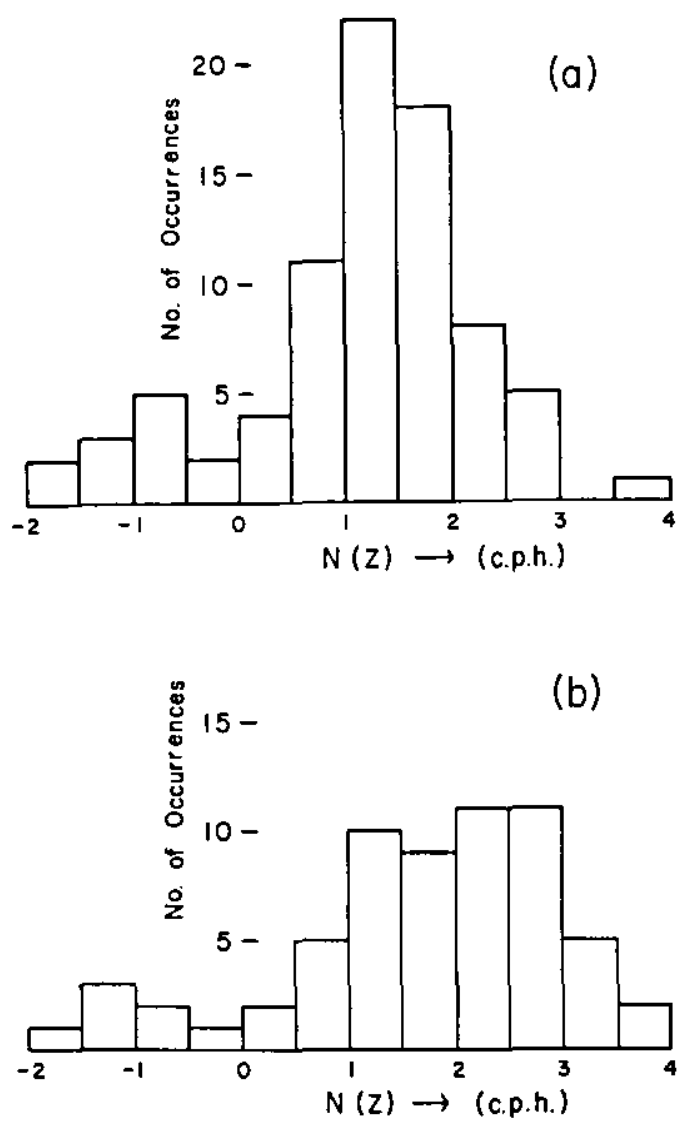

Fig. 19. Histograms of stability for CTD station $19-4$ in interleaving regime when $(a) T_{z}>+0.01^{\circ} \mathrm{C} \mathrm{dbar}^{-1}$ and $(b) T_{2}<-0.008^{\circ} \mathrm{C}$ $\mathrm{dbar}^{-1}$. Mean stabilities for nonnegative $N$ distributions are $(a) 1.5$ $\mathrm{cph}$ and (b) $2.0 \mathrm{cph}$.

magnitude exceeded the mean by a factor of about 9 . Aware that lag correction difficulties are never completely absent, we have examined up traces as well as down traces, since salinity gradients (with respect to time) are of opposite signs and should not bias our results. The buoyancy frequency (Figure 19 ) is larger above warm layers (negative $\partial_{2} T$ ) than below. The result is marginal passing at only the $20 \%$ significance level.

In a theoretical study of double-diffusive effects on lateral mixing of water masses, Stern [1967] predicted many of the results we are now finding. The lateral water mass structure can become unstable, producing intrusions which sink (if cold and fresh) and rise (if warm and salty) across the front. This motion enhances any initial horizontal density gradients and further drives the intrusions. Stern's model required the $\bar{T}_{2}>$ $0, S_{z}>0$ everywhere, not just near intrusions, and is therefore not applicable to the polar front. We feel, however, that much of the physics that his model contains is relevant to the dynamics of the polar front.

The intrusions that we observe have the following characteristics:

1. Interleaving intensity is related to lateral water mass gradients (either horizontal or along a density surface).

2. The dominant vertical scale is $50-100 \mathrm{~m}$.

3. The dominant long-front scale is $6-12 \mathrm{~km}$.

4. Cold (warm) layers get denser (lighter) toward the equator (pole).

5. The slope of intrusions relative to density surfaces is roughly $2-4 \times 10^{-2}$.

6. Intrusions are not due to internal waves.
The flux of heat and salt due to interleaving supports a possible mechanism of AAIW formation or modification first noted by Gordon et al. [1977]. The water mass AAIW found at depths $600-1000 \mathrm{~m}$ north of the subantarctic front and at shallower depths south of this front as a "nearly isohaline layer' may be created or modified by diffusive fluxes due to interleaving with no net volume transport away from the polar regions. The effectiveness of interleaving in this context is difficult to judge in view of our lack of information about AAIW formation rates. Based upon our limited data, however, it would seem that interleaving in the polar front plays an important role in the thermodynamic balances of the Southern Ocean. If one takes a $500-\mathrm{m}$ deep region at the polar front and extends it around Antarctica a distance of $2 \times 10^{7} \mathrm{~m}$ together with our estimates of heat/salt transport, one obtains integrated fluxes of $7 \times 10^{9} \mathrm{~g} / \mathrm{s}$ and $8.6 \times 10^{12} \mathrm{cal} / \mathrm{s}$, both fluxes being poleward. Gordon and Taylor's [1975] estimates of freshwater input south of the polar front due to excess of precipitation over evaporation and antarctic runoff are $-10.9 \times 10^{9}$ $\mathrm{g} / \mathrm{s}$. They also estimate an annual heat loss to the atmosphere of $-9.6 \times 10^{13} \mathrm{cal} / \mathrm{s}$. Though the fluxes of salt across the front can nearly balance surface inputs, only about $10 \%$ of surface heat loss can be restored by intrusive fluxes across the polar front. The remainder must come from other processes, such as ring formation, possibly baroclinic instability (as suggested by Bryden), and by antarctic bottom water formation. We are aware that our own estimates are uncertain owing to a lack of knowledge about small-scale diffusivities; we also note that the extension of our Drake Passage results to annual means for the whole Southern Ocean may be dangerous at best.

\section{SUMmary}

To summarize our findings on the high resolution study of the Antarctic Polar Front, we will list items under several categories.

Spatial survey. Our close-spaced CTD survey was imbedded within one of the high-velocity cores of the AACC in the Drake Passage. The structure of the front could be mapped down to vertical scales of $50-$ to $100-\mathrm{m}$ water mass intrusions. The use of a continuous oxygen probe permitted sections $T, S$, $\sigma_{t}$, and $\mathrm{O}_{2}$ to be drawn. Mapping of intrusions was easier in the down-stream than the cross-stream direction.

Time series. A two-inertial-period time series with 12 profiling current meter stations and 17 CTD stations showed the ensemble-averaged fields to be vertically smooth, the front orientation as determined from horizontal currents agreeing within $19^{\circ}$ with that obtained from XBT and CTD data. Mean vertical shears were comparable to those expected geostrophically from the cross-frontal slope of the density field.

The velocity variability, dominantly due to internal-inertial gravity waves, was decomposed spectrally in the vertical and found to be horizontally isotropic and vertically symmetric. The observed velocities were insulficient to account for the measured temperature variability, thus ruling out internal waves as the source of interleaving. Following constant potential density surfaces the energy containing scales for intrusions $(50-100 \mathrm{~m})$ persisted over several hours consistent with at least $5-10 \mathrm{~km}$ along-current extent. These larger intrusions were density compensating. On scales as large as $20 \mathrm{~m}$ and less this was no longer the case, and excess salinity variability was present. This had implications for the lateral water mass exchange model of Joyce [1977]. Applying this model to the data, cross-frontal heat and salt fluxes were estimated which 


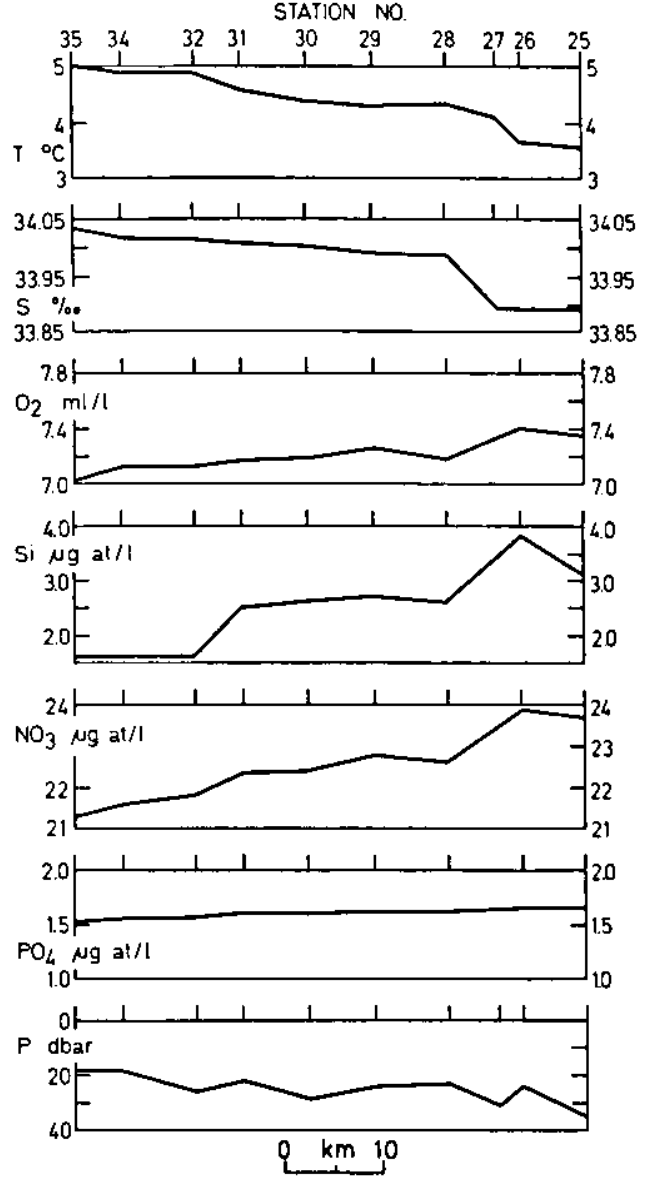

Fig. Al. Cross-frontal near-surface distribution of (a) temperature, $(b)$ salinity, $(c)$ dissolved oxygen, $(d)$ silicate, $(e)$ nitrate, and $(f)$ phosphate. The surface expression of the polar front was encountered near station 27, where horizontal gradients became most eminent. Data were sampled by a CTD rosette, the uppermost bottle of which was released at pressure values shown in the last panel of the figure.

were comparable to those required for Southern Ocean wide salt and to a lesser extent, heat balances.

Double diffusion. Three nearly independent measurements suggest that double diffusion may be important for frontal dynamics. First, the lateral exchange model gives buoyancy fluxes which are up gradient, trying to enhance an existing density slope while at the same time running down horizontal temperature and salinity gradients. Second, cold (warm) intrusions were observed to deepen (become shallow) at a faster rate than potential density surfaces consistent with the idea that cold fresh (warm salty) intrusions get denser (lighter) as they 'move' across a water mass boundary. Finally, static stability was marginally greater above warm salty intrusions than below, where salt fingering would be possible. These three pieces of circumstantial evidence taken separately could be dismissed by a number of arguments. Taken together, however, they suggest that double-diffusive effects are important in oceanic thermohaline fronts.

Reproducibility. In many respects the techniques employed in this work are new to the problem of the structure and dynamics of the polar front. We take this opportunity to invite scientists with better instrumentation to consider with a critical eye some of our above results for the Antarctic Polar Front, especially those which are sensitive to proper and improper measurement of small-scale, small-amplitude salinity fluctuations. It would be satisfying to see similar findings from other frontal zones.

\section{Appendix: StPplementary Chemical Obsertations Fronthe Polar FroNt ZoNe}

As part of our three-dimensional survey of the Antarctic Polar Front, supplementary discrete observations of nutrients and dissolved oxygen were simultaneously made in conjunction with CTD casts. Details of the autoanalyzer system used have been described by Dahm in the work of Joyce et al. [1976]. Problems occurred with the silicate analysis, leading to doubtful data which have been omitted in our presentation (Figure A2, second panel). It is felt that the precision of the chemical data throughout is better than $1 \%$, probably nearer $0.5 \%$.

In Figure Al we present a collection of shallow samples from the cross-frontal section (stations 25-35). They have been taken from the uppermost rosette bottles. The depth from which these 'surface' probes originate differs between 18 and $35 \mathrm{~m}$, shown in Figure Al, seventh panel, as pressure readings.

In the second section we found that the subsurface temperature field was highly convoluted with no single adjacent pair of stations that could be said to span the front. The surface expression, however, is most dramatic between CTD stations 26 and 28 with notable changes in all but one of the measured variables; poleward drops of temperature $\left(\Delta T=-0.72^{\circ} \mathrm{C}\right)$ and salinity $(\Delta S=-0.12 \%)$; and increases of dissolved oxygen $\left(\Delta \mathrm{O}_{2}=0.23 \mathrm{ml} / \mathrm{l}\right)$, silicate $\left(\Delta \mathrm{SiO}_{4}=1.2 \mu \mathrm{g}\right.$ atom $\left./ \mathrm{l}\right)$, and nitrate $\left(\Delta \mathrm{NO}_{3}=1.3 \mu \mathrm{g}\right.$ atom/l $)$. All of the above occurred in a horizontal distance of $7 \mathrm{~km}$. Since the near-surface bottle data from station 27 was unavailable, the actual gradients across the front may have been greater. No significant gradient in phosphate is obvious from Figure Al, sixth panel.

The oxygen increase can be explained by the $\mathrm{O}_{2}$ saturation across the front: stations 28 and 26 both show a $99 \%$ saturation value for oxygen. The jump in silicate is correlated with the surfacing of the $4^{\circ} \mathrm{C}$ isotherm, one of several such occurrences on the cruise as was noted by Dahm in the work of Joyce et al. [1976]. Figure Al, fourth panel, further confirms the usefulness of silicate as a 'year-round' parameter for the definition of the surface expression of the polar front. Its relative increase across the front was $46 \%$, unaffected by seasonal masking effects found often in surface temperature and salinity data from this region.

Finally, it might be of interest to mention that the continuous air temperature record (not shown here) from the observation deck of the ship indicated a drop of $\Delta T_{a}=-3^{\circ} \mathrm{C}$, which can be correlated, if already known, with the front passage between stations 28 and 26 .

Last, we discuss the combined $\mathrm{O}_{2}, \mathrm{Si}, \mathrm{NO}_{3}$, and $\mathrm{PO}$, sections from our small-scale investigation. They were obtained during the up traces of the CTD casts that yielded the down-trace data in Figure 7. A comparison between oxygen sections prepared from continuous profiles in Figure $7 d$ and from discrete samples in Figure A2, first panel, both obtained in the same environment at nearly the same time, demonstrates typical aliasing effects and gives us a subjective measure for reliability of finer features in the nutrient parameters, which could not be sampled continuously. A good example for a possible misleading interpretation is the disconnected $4.25-\mathrm{ml} / \mathrm{l}$ line in 1000-m depth at station 28 in Figure A2, first panel. Comparing this figure with Figure $7 d$ we realize that we missed the continuation of the $\mathrm{O}_{2}$ minimum layer across station 28 . The data in Figure A2, fourth panel, are simply undersampled. 

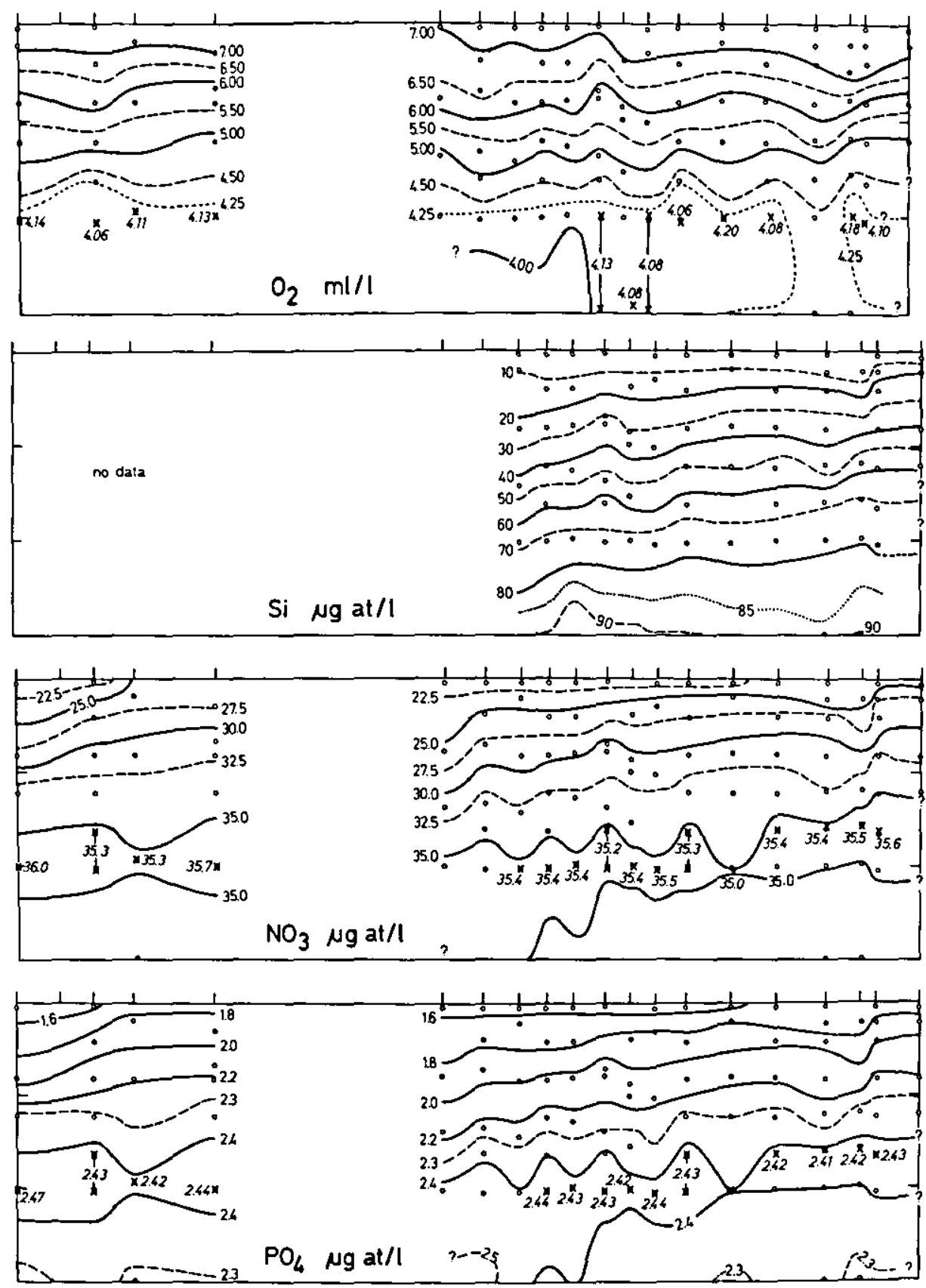

$\mathrm{km} 10$

Fig. A2. Front parallel (left) and front normal (right side) sections through the southern extent of the Antarctic Pola1 Front zone. Under our convention the front was situated between stations 26 and 28 . Data were obtained by discrete bottle samples tripped on up-trace CTD casts (shown in Figure 7; down traces contoured in). Depth of samples are labeled by circles and extreme values by crosses. Note the different slope of $\mathrm{O}_{2}$ and $\mathrm{NO}_{3} / \mathrm{PO}_{4}$ isolines (first, third, and fourth panels). $\mathrm{O}_{2}, \mathrm{NO}_{3}$, and $\mathrm{PO}$, show pronounced extrema, although $\mathrm{O}_{2}$ and $\mathrm{NO}_{3} / \mathrm{PO}_{4}$ in different depths: the $\mathrm{SiO}_{4}$ (second panel) distribution increases at all depths.

Observed extreme values in Figure A2 have been labeled by crosses. They appear in all but one station roughly below 1100 . $\mathrm{m}$ depth. Silicate (second panel) data show no intermediate extrema, although the vertical Si gradient decreases with increasing depth. The depletion of dissolved oxygen (first panel) coincides with excess content of nitrate (third panel) and phosphate. In general, these findings are representative for antarctic regions. They reflect decomposition of biological substances in the intermediate, upper circumpolar deep water. While nitrate and phosphate concentrations, in approximately equal ratios, mainly increase because of slowly sinking soft parts of the organisms, silicate is freed by heavy, rapidly sinking skeletal structures for which the duration time in intermediate depths is too short to build up a silicate maximum [Sverdrup et al., 1942, p. 237].

Of further interest is the deviation of the $\mathrm{O}_{2 \min }$ and the $\mathrm{NO}_{3_{\max }} / \mathrm{PO}_{4_{\max }}$ layers in depth. All available samples from stations 25-39 have been interpolated parabolically in the depth range of the extrema. Estimates of the depths obtained in this way were ensemble averaged across the section. The 
calculated depth of the $\mathrm{O}_{2}$ minimum was found at $1360 \mathrm{~m}$ and that of the $\mathrm{NO}_{3}$ and $\mathrm{PO}$, maxima at $1120 \mathrm{~m}$. Consequently, the average $\mathrm{O}_{2_{\mathrm{min}}}$ layer is $240 \mathrm{~m}$ below the nutrient maximum.

In this appendix we could only discuss a subgroup of available chemical data from the polar front zone obtained during our Isos contribution. Optical measurements made during the cross-frontal section have been presented separately by $K u l l e n-$ berg [1978]. More evaluation of the water samples is reserved for future analysis.

Acknowledgments. We wish to express our thanks to the scientists and crew aboard the Thompson, who helped us collect the data, to Worth Nowlin for the access to hitherto unpublished hydrographic data, and to John Woods, Dan Georgi, and colleagues at W.H.O.I. for valuable discussions. This work was supported by National Science Foundation grants OCE 7514056 and OCE 7782036 . One of us (W.Z.) wishes to acknowledge a travel grant instrumental in the joint writing of this research (DFG, Bonn-Bad Godesberg). This paper is contribution 4125 of the Woods Hole Oceanographic Institution.

\section{REFERENCES}

Botnikov, N. N., Geographical position of the Antarctic Convergence Zone in the Antarctic Ocean, Soviet Antarctic Exped. Infor. Bull. Engl. Transl., 4, 324-327, 1963.

Bryden, H. L., Poleward heat flux and conversion of available potential energy in Drake Passage, J. Mar. Res., in press, 1978.

Fofonoff, N. P., and F. Webster, Current measurements in western Atlantic, Phil. Trans. Roy Soc. London. Ser. A, 270, 423-436, 1971.

Fofonoff, N. P.. S. Hayes, and R. Millard, WHOI/Brown CTD microprofiler: Methods of calibration and data handling, Tech. Rep. 74-89. Woods Hole Oceanogr. Inst., Woods Hole, Mass., 1974.

Garrett, C., Mixing in the ocean interior, paper presented at Joint Study Conference on General Circulation Models of the Ocean and Their Relationship to Climate, JOC/SCOR, Helsinki, 1977.

Georgi, D. T., Fine structure in the Antarctic Polar Front zone: Its characteristics and possible relationship to internal waves, $J$. Geophys. Res., 83, in press, 1978.

Gordon, A. L., Structure of antarctic waters between $20^{\circ} \mathrm{W}$ and $170^{\circ} \mathrm{W}$, Antarctic Map Folio Ser., folio 6, edited by V. Bushnell, Amer. Geogr. Soc., New York, 1967.

Gordon, A. L., Antarctic Polar Front zone, in Antarctic Oceanology I, Antarctic Res. Ser., vol 15, edited by J. L. Reid, p. 206, AGU, Washington, D. C.. 1971.

Gordon, A. L., and H. W. Taylor, Heat and salt balance within the cold waters of the world ocean numerical models of ocean circulation, ISBN 0-309-02225-8, pp. 54-56, Nat. Acad. of Sci., Washington, D. C., 1975.
Gordon, A. L., D. T. Georgi, and H. W. Taylor. Antarctic Polar Front zone in the Western Scotia Sea-Summer 1975, J. Phys. Oceanogr., 7.(3), 309-328, 1977.

Jenkins, G. and D. Watts, Spectral Analysis and lis Applications, Holden-Day, San Francisco, 1969.

Johnson, C. L., C. S. Cox, and B. Gallagher, The separation of waveinduced and intrusive oceanic fine structure, J. Phy.s. Oceanogr., in press, 1978.

Joyce, T. M., Observations of the polar front during FDRAKE, 1976: R/V Thompson leg 3, Antarctic J. U.S., XI(3), 157-158, 1976a.

Joyce, T. M., Large scale variations in small scale temperature/salinity finestructure in the main thermocline in the northwest Atlantic, Deep Sea Res., 23, 1175-1136, $1976 b$.

Joyce, T. M., A note on the lateral mixing of water masses, J. Phys. Oceanogr., 7(4), 626-629, 1977.

Joyce. T. M., and S. L. Patterson, Cyclonic ring formation at the polar front in the Drake Passage, Nature, 265(5590), 131-133, 1977.

Joyce, T. M. J. Dean, M. McCartney, R. Millard, D. Moller, A. Voorhis, C. Dahm, D. Georgi, G. Kullenberg, J. Toole, and W. Zenk, Observations of the Antarctic Polar Front during FDRAKE 76: A cruise report, Tech. Rep. 76-74. Woods Hole Oceanogr. Inst., Woods Hole, Mass., 1976.

Kullenberg, G., Light scattering as a means of studying frontal zones, J. Geophys. Res., 83, in press, 1978.

Leaman, K. D., and T. B. Sanford, Vertical energy propagation of internal waves: A Vector spectral analysis of velocity profiles, $J$. Geophys. Res., 80(15), 1975-1978, 1975.

Montgomery, R. B., Circulation in upper layers of southern North Atlantic deduced with use of isentropic analysis, Pap. Phys. Oceanogr. Meteorol., VI(2), 1938.

Nowlin, W. D., R. D. Pillsbury, L. I. Gordon, G. C. Anderson, and D. J. Baker Contributions of R/V Thompson legs 1 and 2 to FDRAKE, 1976, Antarctic J. U.S., XI(3), 154-156, 1976.

Nowlin, W. D., T. Whitworth, and R. D. Pillsbury, Structure and transport of the Antarctic Circumpolar Current at Drake Passage and short term measurements. J. Phys. Oceanogr., 7, 788-802, 1977.

Patterson, S. L., and H. A. Sievers, Contributions of AGS Yelcho to FDRAKE, 1976, Ant. J. U.S. XI(3). 158-159, 1976.

Stern, M. E., Lateral mixing of water masses, Deep Sea Res., 14, $747-$ $753,1967$.

Sverdrup, H., M. Johnson, and R. Fleming. The Oceans, PrenticeHall, Englewood Clifts, N. J., 1942.

Turner, J. S., Buorancy Effects in Fluids, Cambridge University Press, New York, 1973.

Turner, J. S., Double-diffusive intrusions into a density gradient, $J$. Geophys. Res., 83, 2887, 1978.

(Received March 20, 1978 ; revised June 6, 1978: accepted June 12, 1978.) 